\title{
Laminin $\alpha 2$ Chain (M Chain) Is Found within the Pathway of Avian and Murine Retinal Projections
}

\author{
Nathalie Morissette and Salvatore Carbonetto \\ Centre for Research in Neuroscience, McGill University and Montreal General Hospital Research Institute, \\ Montreal, Quebec, Canada H3G 1A4
}

Laminin-1 is found at the end-feet of neuroepithelial cells along the outer margin of the optic pathway during early stages of development. Prior to the establishment of most retinal projections in vivo, laminin-1 expression becomes restricted to basement membranes associated with the eye and optic pathway. We report that, in contrast to the $\alpha 1$, $\beta 1$, and $\gamma 1$ chains of laminin-1, laminin $\alpha 2$ chain (formerly laminin $M$ chain) is expressed within the pathway of avian and murine retinal ganglion cell (RGC) growth cones as they extend into the optic nerve, across the optic chiasm and into the brain. Expression of laminin $\alpha 2$ chain is reduced soon after formation of the visual projections but nevertheless maintained at non-basal lamina sites within the adult optic nerve. Laminin $\alpha 2$ chain, in contrast to laminin- 1 chains, is also highly expressed in the developing avian tectobulbar pathway. Chick optic nerve-derived type-1 astrocytes in culture express laminin $\alpha 2$ chains as extracellular fibrils on their surface. Laminin $\alpha 2$ chain was also detected on the surface of cultured embryonic retinal neurons and developing RGCs. These results suggest that astrocytes and/or RGCs may synthesize laminin $\alpha 2$ chain along the developing optic pathway, and imply that laminin $\alpha 2$ chain-in a complex with non- $\beta 1$ and non- $\gamma 1$ laminin chains-may serve as an adhesive substrate and possibly as a guidance cue for elongating RGC growth cones in vivo.

[Key words: chick retina, mouse retina, retinal ganglion cells, optic pathway, tectobulbar pathway, laminin, merosin]

Growth cones of retinal ganglion cells (RGCs) navigate towards their brain targets along a highly stereotyped route. Target ablation studies (Reh et al., 1983; Taylor, 1990) and recent in vivo manipulations (Fraser et al., 1988; Harris, 1989; Sretavan and Reichardt, 1993) have provided compelling cvidence that local cues encountered along the optic pathway regulate the outgrowth of RGC axons. In vitro experiments have further demonstrated

\footnotetext{
Received Apr. 11, 1995; revised Aug. 9, 1995; accepted Ang. 14, 1995

We are grateful to Dr. E. Engvall (La Jolla Cancer Center), Dr. T. Frankfurter (University of Virginia), and Dr. P.L. Jeffrey (University of Sydney) for generously supplying us with polyclonal antiserum to human placental merosin, monoclonal antibody to chick $\beta$ III-tubulin, and monoclonal antibody to chick Thy.1, respectively. This work was supported by Grant MT-9000 to S.C. from the Medical Research Council (MRC) of Canada. N.M. was the recipient of an MRC studentship.

Correspondence should be addressed to Salvatore Carbonetto, Ph.D., Montreal General Hospital Research Institute, 1650 Cedar Avenue, Livingston Hall, Room L7-121, Montreal, Quebec, Canada H3G 1 A4.

Copyright (C) 1995 Society for Neuroscience 0270-6474/95/158067-16\$05.00/0
}

the influence on RGC outgrowth of adhesive interactions with substrate-bound molecules. To date, several cell surface molecules and components of the extracellular matrix (ECM) have been identified which stimulate (reviews: Reichardt and Tomaselli, 1991; Reichardt et al., 1992) or inhibit (Snow et al., 1991; review, Keynes and Cook, 1990) RGC axonal extension. The restricted in vivo distribution of substrate-bound molecules along the optic pathway may therefore be the mechanism by which growth and directional cues are imparted to RGC growth cones bearing the appropriate receptors.

Developing RGCs express several receptors which are members of the integrin family of adhesive molecules (revicws: Reichardt et al., 1990, 1992; Hynes et al., 1992). Integrins are $\alpha \beta$ heterodimeric complexes with distinct ligand-binding specificities. They function in a wide variety of tissues in cell-cell and cell-ECM interactions. ECM ligands for integrins present on RGCs include collagens, vitronectin, and laminins. The potent activity of laminin-1 (Engelbreth-Holm-Swarm laminin; $\alpha 1 \beta 1 \gamma 1$ complex; revised laminin nomenclature, Burgeson et al., 1994) in promoting neurite outgrowth by central and peripheral neurons in vitro (revicw, Sanes, 1989) and the developmental regulation of laminin-binding integrin function in RGCs (Cohen et al., 1986; Cohen and Johnson, 1991; de Curtis et al., 1991) led some groups to explore the distribution of laminin-1 in developing optic pathways. Earlier immunohistochemical analyses revealed that laminin- 1 is expressed transiently during development and may provide a substrate for early RGC axons but is unlikely to guide the majority of RGC axons to their targets in the brain (Cohen et al., 1987; Liesi et al., 1988). Interestingly, laminin-2 (mcrosin; $\alpha 2 \beta 1 \gamma 1$ complex) was recently reported to be more potent than laminin-1 in promoting integrin-dependent neurite outgrowth by developing avian and mammalian RGCs in vitro (Cohen and Johnson, 1991). These findings prompted us to investigate whether laminin- 2 could serve as a substrate for elongating RGC axons in vivo.

We report that, in contrast to laminin-1 chains, laminin $\alpha 2$ chain is expressed in the pathway of chick and mouse RGC axons at developmental times consistent with a growth-promoting role in vivo. Thus, a laminin complex comprising an $\alpha 2$ chain, a non- $\beta 1$ chain and a non- $\gamma 1$ chain may serve as an adhesive substrate for elongating RGC growth cones. In addition, cell culture data indicate that type- 1 astrocytes in developing optic nerves and embryonic RGCs express laminin $\alpha 2$ chains on their surface, thereby suggesting that they may synthesize laminin $\alpha 2$ chain in vivo. Finally, laminin $\alpha 2$ chain is also shown to be highly expressed within the developing tectobulbar pathway. 
Part of this work has been presented previously in abstract form (Morissette and Carbonetto, 1993).

\section{Materials and Methods}

\section{Cell cultures}

Substratum preparation. Circular glass coverslips in 24-well disposable dishes were precoated with poly-L-ornithine (PLO; $50 \mu \mathrm{g} / \mathrm{ml}$ in 0.015 $\mathrm{M}$ borate buffer, $\mathrm{pH}$ 8.4) and incubated with human placental merosin (laminin-2; GIBCO; $0.5 \mu \mathrm{g} / \mathrm{ml}$ in Ham's F12 medium) or EngelbrethHolm-Swarm laminin (laminin-1) purified as described previously (Douville et al., 1988; $0.5 \mu \mathrm{g} / \mathrm{ml}$ in Ham's F12 medium). Coated coverslips were blocked with bovine serum albumin $(2 \%$ in $0.05 \mathrm{M}$ carbonate buffer, $\mathrm{pH} 9.6$ ) to eliminate nonspecific attachment of cells to uncoated or poorly coated regions of glass coverslips.

Retinal cell cultures. Embryonic days 6 and 7 chick retinae were dissected free of retinal pigment epithelium and trypsinized as described previously (Cohen et al., 1986). Following trituration of retinal tissues in $\mathrm{Ca}^{2+}$ - and $\mathrm{Mg}^{2+}$-free Hanks' balanced salt solution containing deoxyribonuclease type- $1(0.04 \mathrm{mg} / \mathrm{ml})$ and soybean trypsin inhibitor $(0.5 \mathrm{mg} /$ $\mathrm{ml}$ ), dissociated retinal cells were resuspended in defined culture medium: a 1:1 mixture of DMEM/Ham's F12 culture medium (GIBCO) supplemented with $1.75 \mathrm{~g} / \mathrm{l}$ glucose, $5 \mu \mathrm{g} / \mathrm{ml}$ insulin, $30 \mathrm{~nm}$ selenium, $25 \mu \mathrm{g} / \mathrm{ml}$ iron-saturated ovotransferrin, $100 \mu \mathrm{g} / \mathrm{ml}$ human transferrin, $100 \mathrm{U} / \mathrm{ml}$ penicillin and streptomycin (Bottstein et al., 1980; de Curtis et al, 1991). The $6 \mathrm{~d}$ and $7 \mathrm{~d}$ retinal cell suspensions were then preplated onto uncoated tissue culture dishes to remove any contaminating pigment epithelial cells which preferentially adhere to these dishes $(15$ min at $37^{\circ} \mathrm{C}$ in a $5 \% \mathrm{CO}_{2}$ atmosphere). Retinal ncurons were collected and seeded onto coated coverslips at a final density of $1-2 \times 10^{5}$ cells/ $\mathrm{ml}$ in presence of $2 \%$ fetal bovine serum. Epithelia-free $8 \mathrm{~d}, 9 \mathrm{~d}$, and 12 d embryonic chick retinae were isolated and incubated with papain as described elsewhere (Leifer et al., 1984; Cohen and Johnson, 1991). Dissociated retinal neurons were resuspended in defined culture medium (see above) supplemented with progesterone $(6 \mu \mathrm{g} / \mathrm{ml})$, putrescine $(16.1$ $\mu \mathrm{g} / \mathrm{ml}$ ), and $2 \%$ fetal bovine serum, and seeded without preplating onto coated coverslips. For neurite outgrowth assay, retinal neurons were cultured for $16 \mathrm{hr}$ at $37^{\circ} \mathrm{C}$ in a $5 \% \mathrm{CO}_{2}$ atmosphere onto coverslips coated with laminin- 1 or laminin-2. To assay laminin $\alpha 2$ chain expression, $7 \mathrm{~d}$ retinal neurons were cultured for $2 \mathrm{~d}$ onto coverslips coated with laminin-1.

Purification of RGCs for culture. Embryonic day 7 chick RGCs were purified from trypsin-dissociated retinal tissues by antibody-mediated adhesion ("panning") (Lehwalder èt al., 1989). Briefly, tissue culture petri dishes were first coated with goat anti-mouse IgGs (1:100 dilution in phosphate buffered saline solution, PBS; overnight at $4^{\circ} \mathrm{C}$ ), followed by incubation with monoclonal antibody against chick Thy.1 (SB1 1.42; $2.5 \mu \mathrm{g} / \mathrm{ml}$ in PBS; $2 \mathrm{hr}$ at $4^{\circ} \mathrm{C}$; gift of Dr. P. L. Jeffrey, Children's Hospital Research Foundation and the University of Sydney, Australia). Dissociated retinal cells from $7 \mathrm{~d}$ chick embryos were prepared as described earlier and plated, without preplating, in defined culture medium onto Thy. 1-coated dishes $\left(10-15 \mathrm{~min}\right.$ at $37^{\circ} \mathrm{C}$ in a $5 \% . \mathrm{CO}_{2}$ atmosphere). Nonadherent cells were subsequently removed by gentle washing in $\mathrm{Ca}^{2+}$ and $\mathrm{Mg}^{2+}$-free HBSS culture medium (GIBCO; $\approx 5-8$ washes). Finally, adherent RGCs were collected by vigorous washing in DMEM/ F12 culture medium and plated at a density of $10^{5}$ cells $/ \mathrm{ml}$ onto tissue culture dishes coated with laminin- 1 . Cultures were incubatcd for $\approx 40$ hr at $37^{\circ} \mathrm{C}$ in a $5 \% \mathrm{CO}_{2}$ atmosphere.

Glial cell cultures. Optic nerves dissected from $8 \mathrm{~d}, 12 \mathrm{~d}$, or $15 \mathrm{~d}$ chick embryos were minced with scissors and incubated with $0.05 \%$ trypsin and papain (Leifer et al., 1984), followed by trituration in $\mathrm{Ca}^{2+}$ and $\mathrm{Mg}^{2+}$-free Hanks' balanced salt solution containing deoxyribonuclease type-1 $(0.04 \mathrm{mg} / \mathrm{ml})$ and soybean trypsin inhibitor $(0.5 \mathrm{mg} / \mathrm{ml})$. Dissociated cells were resuspended in high glucose DMEM culture medium containing $10 \%$ fetal bovine serum (DMEM/10\% FBS) and seeded onto PLO-coated coverslips for $3-4 \mathrm{~d}$ at $37^{\circ} \mathrm{C}$ in a $5 \% \mathrm{CO}_{2}$ atmosphere.

\section{Histological procedures}

Adult chickens, embryonic chicks, and embryonic mice were decapitated, and their eyes or entire heads were fixed at $4^{\circ} \mathrm{C}$ by overnight immersion in periodate-lysine-paraformaldehyde (2\%) solution (PLP) (McLean and Nakane, 1974). Adult mice were anesthetized with $7 \%$ chloral hydrate and perfused through the heart with $10 \mathrm{ml}$ of PLP solution; their eyes and optic nerves were postfixed in PLP solution for 1 hr at room temperature (RT). Tissues were cryoprotected at $4{ }^{\circ} \mathrm{C}$ by overnight immersion in PBS containing 20\% sucrose. Cryoprotected tissues were then embedded (OCT compound; Miles) and frozen in liquid nitrogen-cooled isopentane $\left(70^{\circ} \mathrm{C}\right)$. Sections were cut on a cryostat (10-12 $\mu \mathrm{m}$; Leitz), dried onto Superfrost/Plus slides (Fisher Scientific) and stored at $4^{\circ} \mathrm{C}$.

\section{Immunolabeling}

Retinal tissues and developing optic pathways. Cryosections were first incubated for $20 \mathrm{~min}$ in a $4: 1$ solution of methanol:hydrogen peroxide (3\%) to eliminate endogenous peroxidase activity. Sections were then permeabilized in $0.25 \mathrm{~mm}$ Tris-buffered saline (TBS) containing $0.1 \%$ Triton X-100 (TBS-X; $2 \times 10 \mathrm{~min}$ at RT) followed by incubation with $10 \%$ normal goat serum (chick tissues) or $10 \%$ fetal bovine serum (mouse tissues) in TBS-X to block binding of secondary antibodies with the specimen ( $30 \mathrm{~min}$ at RT). Sections were equilibrated overnight at $4^{\circ} \mathrm{C}$ with primary antiserum in TBS supplemented with $1 \%$ normal goat serum or $1 \%$ fetal bovine serum (TBS/1\% FGS). Either an affinitypurified rabbit polyclonal antiserum raised against a $65 \mathrm{kDa}$ pepsin subfragment of human placental merosin comprising repeats 4 and 5 of the $\alpha 2$ chain $\mathrm{G}$ domain (polyclonal anti- $\alpha 2 ; 5-6 \mu \mathrm{g} / \mathrm{ml}$; Leivo and Engvall, 1988) or an IgG-purified polyclonal antiserum raised against mouse Engelbreth-Holm-Swarm laminin (polyclonal anti- $\alpha 1 \beta 1 \gamma 1 ; 5-10 \mu \mathrm{g} /$ $\mathrm{ml}$; generated in this lab) were used as primary antiserum. Tissue sections incubated in the absence of primary antiserum or in the presence of normal rabbit serum $(5 \mu \mathrm{g} / \mathrm{ml})$ were used as controls. Subsequently, sections were rinsed in TBS and incubated with biotinylated goat antirabbit IgGs $(2.5 \mu \mathrm{g} / \mathrm{ml}$ in TBS/1\%FGS; $1 \mathrm{hr}$ at RT; Vector Labs) followed by rinsing and incubation with avidin-horseradish peroxidase (HRP) complexes ( $1 \mathrm{hr}$ at RT; Vectastain ABC kit; Vector Labs). Finally, immunolabeled tissues were rinsed in $0.02 \mathrm{M}$ Tris buffer solution containing $0.05 \%$ imidazole (TBI; $3 \times 10 \mathrm{~min}$ at RT) and reacted for 6-8 min using $0.6 \mathrm{mg} / \mathrm{ml}$ diaminobenzidine tetrahydrochloride in TBI. Reacted sections were rinsed in distilled water, dehydratcd in $50 \%, 70 \%$, $90 \%$, and $99 \%$ ethanol solutions, and mounted using Entellan (Merck).

Cultured chick retinal neurons- $\beta$-tubulin expression. To show the neuronal composition of primary retinal cell cultures, cultured retinal cells were fixed and permeabilized for $20-30$ min at $25^{\circ} \mathrm{C}$ in PHEM buffer (60 mM PIPES, $25 \mathrm{mM}$ HEPES, $10 \mathrm{mM}$ EGTA, and $2 \mathrm{~mm} \mathrm{MgCl}_{2}$, $\mathrm{pH}$ 6.9) containing $0.4 \%$ glutaraldehyde and $0.2 \%$ Triton X-100 (Letourneau et al., 1986). Fixed cells were washed in sodium borohydride ( $1 \mathrm{mg} / \mathrm{ml}$ in water for $15 \mathrm{~min}$ ) and incubated for $30 \mathrm{~min}$ at $25^{\circ} \mathrm{C}$ with a polyclonal antibody against chick $\beta$-tubulin (Sigma; 1:100 dilution in DMEM $/ 10 \%$ FBS), followed by biotinylated goat anti-rabbit IgGs and fluorescein-conjugated streptavidin (1:200 dilution; RPN 1232, Amersham). Fluorescein-labeled cells were mounted using Immunofluore medium (ICN). For RGC neurite outgrowth assay, RGCs in dissociated retinal cell cultures were identified by immunoperoxidase labcling using a monoclonal antibody against the neuron-specific class III $\beta$-tubulin isotype, monoclonal antibody TUJ1 (gift of Dr. T. Frankfurter, U. of Virginia, Charlottesville). Monoclonal antibody TUJ1 has been reported previously to specifically label RGCs in embryonic chick tissues (Watanabe et al., 1991). Briefly, retinal neurons seeded onto coated glass coverslips were fixed and permeabilized in PHEM buffer (see above) Fixed cells were then washed in sodium borohydride (see above) and incubated for $30 \mathrm{~min}$ at $25^{\circ} \mathrm{C}$ with monoclonal antibody TUJ1 $(1: 100$ dilution in DMEM/10\%FBS), followed by biotinylated horse antimouse IgGs and avidin-HRP complexes. Immunolabeled cells reacted for $5 \mathrm{~min}$ using $0.6 \mathrm{mg} / \mathrm{ml}$ diaminobenzidine tetrahydrochloride in TBI. Reacted coverslips were dehydrated and mounted as described for tissue sections.

Cultured chick retinal neurons-laminin $\alpha 2$ chain expression. Both live and fixed cultured chick retinal neurons/RGCs were examined for laminin $\alpha 2$ chain expression. Cultured retinal neurons were either firs incubated for 20 min at $37^{\circ} \mathrm{C}$ with primary antibody solution and fixed for 10 min at $25^{\circ} \mathrm{C}$ using $4 \%$ paraformaldehyde in PBS, or first fixed and then incubated with primary antibody solution for $30 \mathrm{~min}$ at room temperature. Ascites fluid containing mouse monoclonal antibody to the $65 \mathrm{kDa}$ pepsin subfragment of human placental merosin comprising repeats 4 and 5 of the $\alpha 2$ chain $G$ domain was used as primary antibody (1:100 dilution in DMEM/10\% FBS; MAB 1922, Chemicon International; see Leivo and Engvall, 1988; referred to as monoclonal anti- $\alpha 2$ ). Labeled cells were then incubated with hintinylated horse anti-mouse IgGs, followed by avidin-HRP complexes or fluorescein-conjugated streptavidin. HRP-labeled cells were visualized and mounted as de- 


\section{A) Mouse EHS} laminin

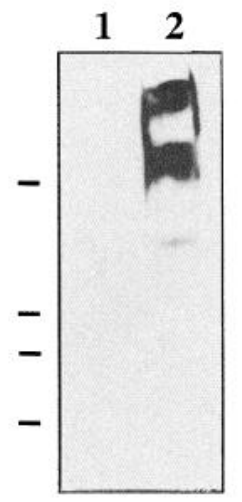

B)

$$
\begin{gathered}
\text { Human } \\
\text { placental } \\
\text { merosin }
\end{gathered}
$$

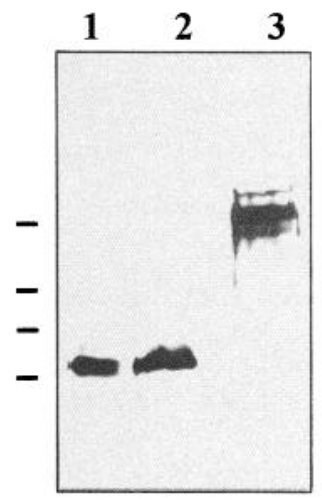

\section{C) Mouse \\ eye \\ extract}

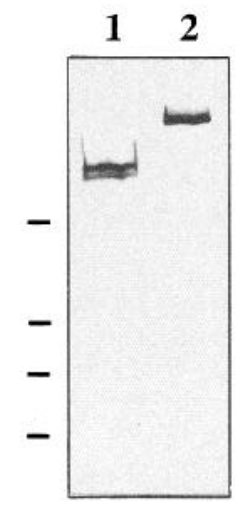

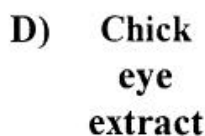

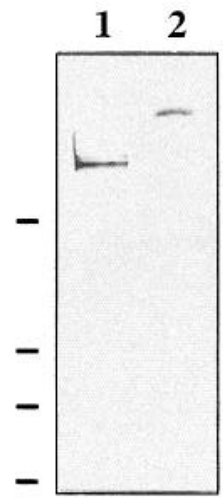

Figure 1. Characterization of antisera to laminin-1 and laminin-2. Laminin-1 expression was detected using an antiserum to mouse EHS laminin (polyclonal anti- $\alpha 1 \beta 1 \gamma 1)$ which recognizes all three laminin-1 chains $(\alpha 1: \approx 400 \mathrm{kDa} ; \beta 1: \approx 215 \mathrm{kDa}$; and $\gamma 1$ : $\approx 205 \mathrm{kDa})$ as well as entactin/ nidogen $(\approx 150 \mathrm{kDa})$ in purified mouse EHS laminin $(A$, lane 2 ; reduced). Expression of laminin-2 $(\alpha 2 \beta 1 \gamma 1)$ was detected using an affinity-purified polyclonal antiserum (polyclonal anti- $\alpha 2)$ which recognizes $\mathrm{a} \approx 70 \mathrm{kDa}(B$, lane 1 ; nonreduced) or a $\approx 80 \mathrm{kDa}(B$, lane 2 ; reduced) polypeptide in purified human placental merosin. In comparison, polyclonal anti- $\alpha 1 \beta 1 \gamma 1$ recognizes the $\beta 1$ and $\gamma 1$ chains of laminin- $2(\approx 215 \mathrm{kDa}$ and $\approx 205$ $\mathrm{kDa})$ but not laminin $\alpha 2$ chain in purified human placental merosin $(B$, lane 3 ; reduced). Polyclonal anti- $\alpha 2$ recognizes a $\approx 300 \mathrm{kDa}(C$ and $D$, lane 1 ; reduced) or a $\approx 380 \mathrm{kDa}(C$ and $D$, lane 2 ; nonreduced) polypeptide in extracts of $2 \mathrm{~d}$ postnatal mouse eyes $(C)$ and $7 \mathrm{~d}$ embryonic chick eyes $(D)$. Proteins were electrophoresed on $6 \%(A, C, D)$ or $7.5 \%(B)$ polyacrylamide gels, and detected as described in the Materials and Methods section. Incubation of blotted proteins with normal rabbit serum yielded no detectable signal on the immunoblots (for example: $A$, lane 1). Molecular weight markers on the left side of each immunoblot correspond to $200 \mathrm{kDa}, 116 \mathrm{kDa}, 97 \mathrm{kDa}$, and $65 \mathrm{kDa}$.

scribed for tissue sections. Fluorescein-labeled cells were mounted using Immunofluore medium (ICN). No cross-reactivity of the secondary antibodies was observed.

Cultured chick glial cells. Both live and fixed chick optic nervederived glial cells in culture were processed for laminin $\alpha 2$ chain and A2B5 antigen expression. Glial cells seeded onto PLO-coated glass coverslips were either first incubated for $20 \mathrm{~min}$ at $37^{\circ} \mathrm{C}$ in primary antibody solution and fixed for $10 \mathrm{~min}$ at $25^{\circ} \mathrm{C}$ using $4 \%$ paraformaldehyde in PBS, or first fixed and then incubated with primary antibody solution for $30 \mathrm{~min}$ at room temperature. Polyclonal anti- $\alpha 2(5-6 \mu \mathrm{g} / \mathrm{ml}$ in DMEM/10\% FBS) or monoclonal anti-A2B5 (ascites fluid; 1:100 dilution in DMEM/10\% FBS; Eisenbarth et al., 1979) were used as primary antibody. Alternatively, cultured glial cells were fixed using $4 \%$ paraformaldehyde in PBS, permeabilized for $10 \mathrm{~min}$ at room temperature using $0.1 \%$ Triton X-100 in PBS, and incubated for $30 \mathrm{~min}$ at $25^{\circ} \mathrm{C}$ with rabbit polyclonal antiserum to glial fibrillary acidic protein (antiGFAP; 1:100 dilution in DMEM/10\%FBS; Cat\# 345994, Calbiochem). Labeled cells were subsequently incubated with biotinylated goat antirabbit or horse anti-mouse IgGs, followed by fluorescein-conjugated streptavidin. Fluorescein-labeled cells were mounted using Immunofluore medium (ICN). No cross-reactivity of the secondary antibodies was observed.

\section{Immunoblotting}

Chick (embryonic day 7) and mouse (postnatal day 2) eyes were frozen in liquid nitrogen and homogenized in cold PBS containing $1 \mathrm{mM}$ $\mathrm{CaCl}_{2}, 1 \mathrm{mM} \mathrm{MgCl}_{2}, 1 \%$ Triton X-100 and protease inhibitors (PBS/ PI): phenylmethylsulfonyl fluoride ( $1 \mathrm{mM}), n$-ethyl maleimide $(1 \mathrm{mM})$, iodoacetamide $(10 \mathrm{~mm})$, benzamidine $(1 \mathrm{~mm})$, leupeptin $(1 \mathrm{mg} / \mathrm{ml})$, aprotinin $(1 \mathrm{mg} / \mathrm{ml})$, and pepstatin $(1 \mathrm{mg} / \mathrm{ml})$. Cultured glial cells prepared from $15 \mathrm{~d}$ embryonic chick optic nerves and cultured neurons prepared from $7 \mathrm{~d}$ embryonic chick retinae were extracted by resuspension in PBS/PI solution containing $0.1 \%$ Triton X-100. The extracted proteins (10-100 $\mu \mathrm{g} / \mathrm{lane}$ ), purified human placental merosin (laminin2; $12 \mu \mathrm{g} /$ lane; Telios Pharmaceuticals) or purified mouse EHS sarcoma laminin (laminin-1; $12 \mu \mathrm{g} / \mathrm{lane}$ ) were electrophoresed on $6 \%$ or $7.5 \%$ polyacrylamide gels under reducing or nonreducing conditions and transferred to nitrocellulose (Towbin et al., 1979). After transfer, nitrocellulose membranes were blocked overnight in TBS/Tween buffer (10 $\mathrm{mm}$ Tris $\mathrm{pH} 7.5,150 \mathrm{~mm} \mathrm{NaCl}$, and $0.1 \%$ Tween 20) containing 5\% skim milk powder and $3 \%$ bovine serum albumin (TBS/Tween/BSA). The next day, blotted proteins were incubated in TBS/Tween/BSA alone or TBS/Tween/BSA containing normal rabbit serum $(0.5 \mu \mathrm{g} / \mathrm{ml})$, polyclonal anti- $\alpha 2(0.5 \mu \mathrm{g} / \mathrm{ml})$, monoclonal anti- $\alpha 2$ (1:2000 dilution), or polyclonal anti- $\alpha 1 \beta 1 \gamma 1(2.5 \mu \mathrm{g} / \mathrm{ml})$. After washing in TBS/Tween for $30 \mathrm{~min}$, bound antibodies were detected using HRP-conjugated goat anti-rabbit or HRP-conjugated goat anti-mouse IgGs (1 hr; 1:2000 in TBS/Tween/BSA; Boehringer Mannheim) and visualized by chemiluminescence (NEN Renaissance kit).

\section{Results}

\section{Characterization of antisera to laminin-1 and laminin-2}

The chick and mouse optic pathways were examined at different developmental stages for the presence of laminin-1 and laminin- 2 by immunoperoxidase labeling using previously characterized antisera. Laminin-1 expression was detected using a polyclonal antiserum to mouse Engelbreth-Holm-Swarm (EHS) laminin (polyclonal anti- $\alpha 1 \beta 1 \gamma 1$ ) which recognizes all three laminin- 1 chains $-\alpha 1(\approx 400 \mathrm{kDa}), \beta 1(\approx 215 \mathrm{kDa})$, and $\gamma 1$ $(\approx 205 \mathrm{kDa})$ - in purified mouse EHS laminin (Fig. 1A, lane 2$)$. Polyclonal anti- $\alpha 1 \beta 1 \gamma 1$ also identifies a minor band of $\approx 150$ $\mathrm{kDa}$ in purified mouse EHS laminin which most likely represents entactin/nidogen; entactin/nidogen is typically bound to and copurifies with laminin-1 (Mann et al., 1989) (Fig. 1A, lane 2). Expression of laminin-2 along chick and mouse optic pathways was investigated using an affinity-purified antiserum specific for laminin $\alpha 2$ chain (polyclonal anti- $\alpha 2$ ). This antiserum was raised against a $65 \mathrm{kDa}$ pepsin subfragment of human placental merosin comprising repeats 4 and 5 of the $\alpha 2$ chain G domain (Leivo and Engvall, 1988). Nucleotide sequence analysis data indicate that human laminin $\alpha 2$ chain is similar in size and domain structure to human laminin $\alpha 1$ chain (Vuolteenaho et al., 1994). However, in contrast to laminin $\alpha 1$ chain, the predicted $\approx 380$ $\mathrm{kDa}$ laminin $\alpha 2$ chain is cleaved in placental tissue or cleaved as a result of homogenization of placental tissue into two poly- 
Table 1. Growth response of embryonic chick RGCs on laminin-1 and laminin-2

\begin{tabular}{lllrrr} 
& \multicolumn{6}{l}{$\%$ of RGCs with neurites } \\
\cline { 2 - 6 } Substratum & $6 \mathrm{~d}$ & $7 \mathrm{~d}$ & \multicolumn{1}{c}{$8 \mathrm{~d}$} & \multicolumn{1}{c}{$9 \mathrm{~d}$} & \multicolumn{1}{c}{$12 \mathrm{~d}$} \\
\hline Poly-L-ornithine & $10.9 \pm 3.2$ & $10.5 \pm 2.0$ & $6.4 \pm 0.7$ & $0.8 \pm 0.4$ & $0.0 \pm 0.0$ \\
Laminin-1 (EHS laminin) & $88.6 \pm 1.7$ & $87.2 \pm 2.8$ & $41.5 \pm 2.5$ & $13.1 \pm 2.1$ & $11.0 \pm 3.6$ \\
Laminin-2 (merosin) & $93.0 \pm 1.7$ & $84.9 \pm 2.8$ & $44.8 \pm 3.5$ & $37.0 \pm 2.0^{*}$ & $49.0 \pm 4.5^{*}$
\end{tabular}

RGCs in primary retinal cell cultures derived from $6 \mathrm{~d}$ to $12 \mathrm{~d}$ chick embryos were identified by immunoperoxidase labeling using a chick RGC marker, monoclonal antibody TUJ1. The neurite outgrowth response of embryonic chick RGCs on poly-L-ornithine (precoating), laminin-1 or laminin-2 was assessed $16 \mathrm{hr}$ after plating by determining the percentages of RGCs growing neurites longer than two cell diameters. Each value represents the mean \pm SEM of three separate experiments carried out in triplicate. A total of 700-1400 RGCs were counted for each time point.

* Difference from laminin-1 value at the 0.003 probability level (Student $t$ test).

peptides of $300 \mathrm{kDa}$ and $80 \mathrm{kDa}$ (Leivo and Engvall, 1988; Ehrig et al., 1990). The $65 \mathrm{kDa}$ pepsin subfragment of human placental laminin $\alpha 2$ chain used in rabbit immunization was shown to be part of the C-terminal $80 \mathrm{kDa}$ polypeptide (Leivo and Engvall, 1988). Consistent with this finding, polyclonal anti$\alpha 2$ chain recognizes $\mathrm{a} \approx 70 \mathrm{kDa}$ (nonreduced; Fig. $1 B$; lane 1 ) or $\mathrm{a} \approx 80 \mathrm{kDa}$ (reduced; Fig. $1 B$; lane 2 ) polypeptide in purified human placental merosin but no larger polypeptide. In comparison, polyclonal anti- $\alpha 1 \beta 1 \gamma 1$ detects the $\beta 1$ and $\gamma 1$ chains (205$215 \mathrm{kDa}$; Fig. $1 B$; lane 3 ) but not the $\alpha 2$ chain (Fig. $1 B$; lanes 1 and 2 ) in purified human placental merosin. Immunoblot analyses indicate that laminin $\alpha 2$ chain in developing chick and mouse eyes is not processed in the same manner as in human placenta. Polyclonal anti- $\alpha 2$ recognizes $a \approx 300 \mathrm{kDa}$ (reduced; Fig. $1 C, D$; lane 1 ) or $\approx 380 \mathrm{kDa}$ (nonreduced; Fig. $1 C, D$; lane 2) polypeptide in extract of developing chick and mouse eyes, possibly reflecting the presence of a cleavage site as well as a disulphide linkage within the N-terminal domain of the laminin $\alpha 2$ chain polypeptide. Variability in the size of the laminin $\alpha 2$ chain has been reported for other tissues and species (Paulsson and Saladin, 1989; Paulsson et al., 1991).

\section{Developmental distribution of laminin-1 and laminin $\alpha 2$ chain in the chick optic pathway}

Laminin-1 is found at the end-feet of neuroepithelial cells along the outer margin of the optic pathway during the first week of embryonic avian development (Cohen et al., 1987). At later stages and prior to the establishment of most retinal projections (embryonic days 7-10), laminin-1 expression becomes restricted to basal laminae associated with the retina and optic pathway (Goldberg, 1974; Rager, 1980; Cohen et al., 1987). These results therefore suggest that laminin-1 may serve as a transient substrate for early chick RGC growth cones but is unlikely to guide the majority of RGC axons to their targets in the optic tectum (Cohen et al., 1987). An earlier study by Cohen and Johnson (1991) revealed that laminin-2 is more effective than laminin-1 in stimulating integrin-dependent neurite outgrowth by older developing avian and mammalian RGCs in vitro. Consistent with this finding (Table 1 ), we observed that $\approx 90 \%$ of $6 \mathrm{~d}$ and $7 \mathrm{~d}$ embryonic chick RGCs in primary retinal cell cultures bear neurites longer than two cell diameters after 16 hours on laminin-1 or laminin- 2 . In contrast, $\approx 10 \%$ of $9 \mathrm{~d}$ and $12 \mathrm{~d}$ embryonic chick RGCs grow neurites on laminin- 1 but $\approx 45 \%$ of these older developing cells remain capable of extending neurites on laminin-2. These observations prompted us to investigate the expression of laminin- 2 in the developing chick retino-tectal pathway.

In the chick, differentiated RGCs begin to appear in the central retinal area on embryonic day 3 . Axons of the earliest-generated RGCs reach the rostral pole of the optic tectum by embryonic day 6 to arrive at the central tectal area on embryonic day 8 . Following their arrival at the optic tectum, RGCs invade the cellular tectal layers and progressively form synaptic contacts. By embryonic day 11 , the production of RGCs has virtually ceased and the majority of RGC axons have reached their target in the optic tectum (Goldberg, 1974; Rager, 1980).

Embryonic day 5. The expression of laminin-1 and laminin $\alpha 2$ chain within retina and optic nerve on embryonic day 5 is shown in Figure 2. Little laminin-1 expression is detected at this age within the lens (Fig. $2 A$, le) and optic nerve (Fig. $2 A$, n), but expression is clearly detected along the pial limiting membrane that surrounds the optic nerve (Fig. $2 A$, arrows). In com-
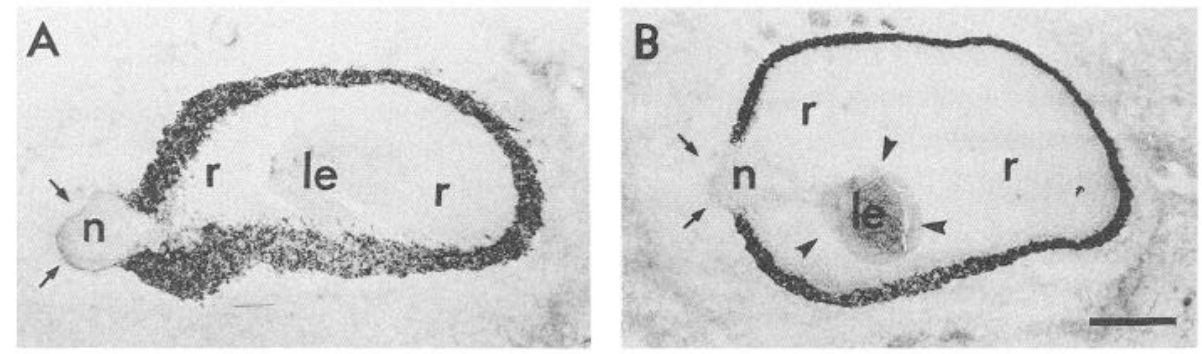

Figure 2. Distribution of laminin-1 and laminin $\alpha 2$ chain within retina and optic nerve of a $5 \mathrm{~d}$ chick embryo. Laminin-1 expression was examined by immunoperoxidase labeling using polyclonal anti- $\alpha 1 \beta 1 \gamma 1(A)$; laminin $\alpha 2$ chain expression was detected using the affinity-purified polyclonal anti- $\alpha 2(B)$. Laminin-1 is weakly expressed at this age within the lens $(A, l e)$ and optic nerve $(A, n)$, but expression is clearly detected within the pial limiting membrane that surrounds the optic nerve $(A$, arrows). In comparison, laminin $\alpha 2$ chain is expressed within the lens $(B, l e)$, optic nerve $(B, n)$ and along the retinal nerve fiber layer $(B$, arrowheads), but no expression is associated with the basement membrane that lines the optic nerve $(B$, arrows). Abbreviations: le, lens; $n$, optic nerve; $r$, retina. Scale bar represents $\approx 165 \mu \mathrm{m}$ in $A$ and $\approx 207 \mu \mathrm{m}$ in $B$. 

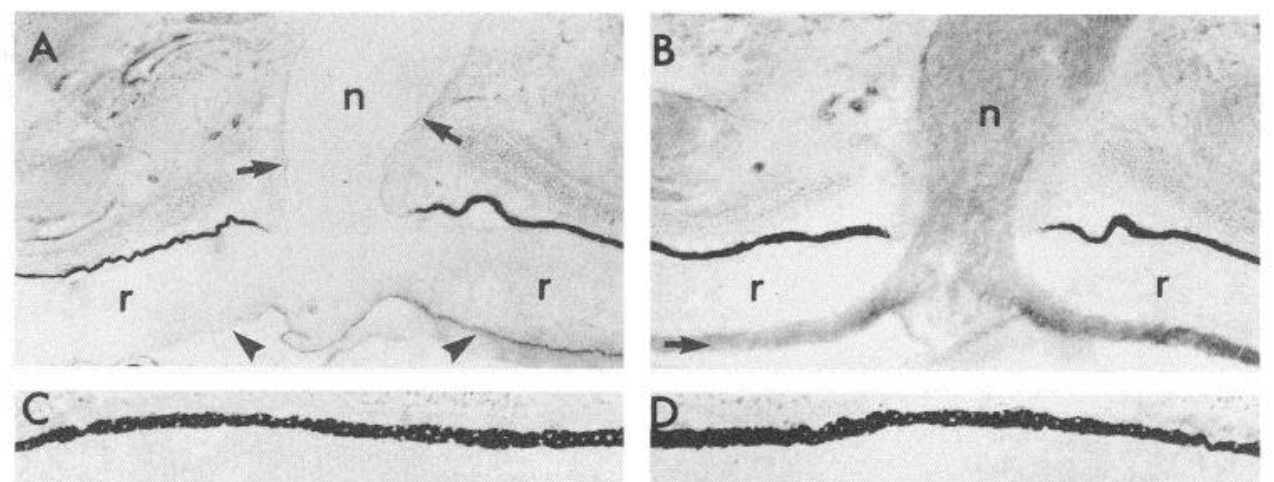

i n I

rgc
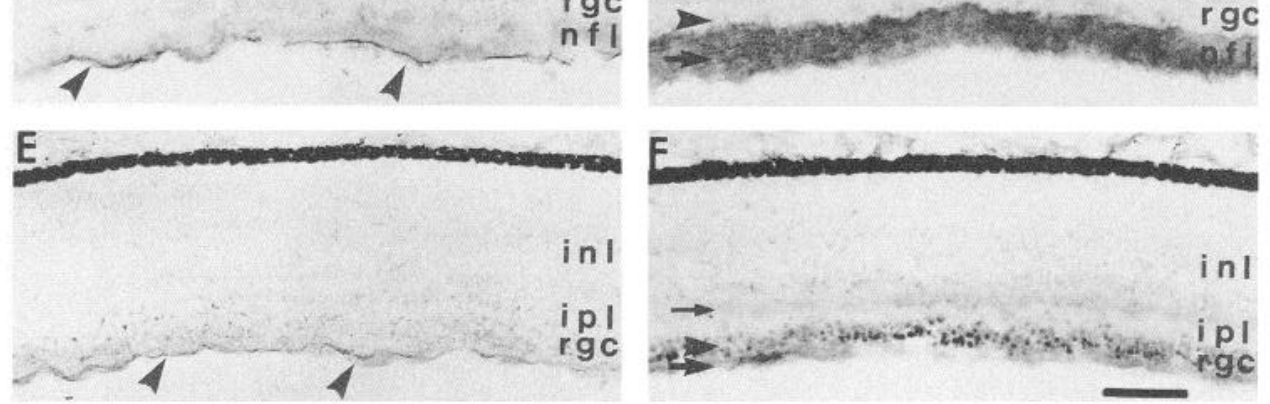

in I

ipl

rgc

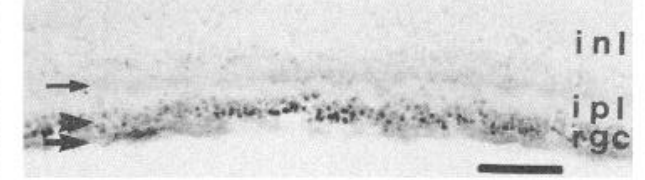

Figure 3. Distribution of laminin-1 and laminin $\alpha 2$ chain within the optic nerve $(A, B)$, central retina $(C, D)$ and paracentral retina $(E, F)$ of an $8 \mathrm{~d}$ chick embryo. Expression of laminin-1 $(A, C$, $E)$ and laminin $\alpha 2$ chain $(B, D, F)$ was detected as in Figure 2. Laminin-1 expression at this age is restricted to the pial limiting membrane which surrounds the optic nerves $(A$, arrows $)$ and to the retinal inner limiting membrane which lines the retina $(A, C, E$; arrowheads). In contrast, laminin $\alpha 2$ chain expression is detected within the retinal nerve fiber layer $(B, D, F$; large arrow) and optic nerves $(B, n)$. In addition, many RGCs in paracentral retina $(F$, arrowhead) but not central retina $(D$, arrowhead) show intense laminin $\alpha 2$ chain immunoreactivity. Weak anti- $\alpha 2$ hain labeling is also detected in paracentral retina within the inner plexiform layer where RGC dendrites develop $(F$, small arrow). Abbreviations in this figure: inl, inner nuclear layer; $i p l$, inner plexiform layer; $n$, optic nerve; $n f l$, nerve fiber layer; $r$, retina; and $r g c$, retinal ganglion cell layer. Scale bar represents $\approx 185 \mu \mathrm{m}$ in $A$ and $B$ and $\approx 75 \mu \mathrm{m}$ in $C-F$. parison, laminin $\alpha 2$ chain is expressed within the lens (Fig. $2 B$, le), optic nerve (Fig. $2 B, \mathrm{n}$ ) and along the retinal nerve fiber layer (Fig. $2 B$, arrowheads). Little laminin $\alpha 2$ chain expression is associated with the basement membrane that lines the optic nerve (Fig. 2B, arrows). No labeling was observed on control sections incubated with normal rabbit serum $(0.5 \mu \mathrm{g} / \mathrm{ml})$ or secondary antibody alone (not shown).

Embryonic day 8. The distribution of laminin-1 and laminin $\alpha 2$ chain within retina and optic nerve on embryonic day 8 is illustrated in Figure 3. As previously reported (Cohen et al., 1987), laminin-1 expression at this age is restricted to basement membranes including the pial limiting membrane that surrounds the optic nerve (Fig. $3 A$, arrows) and the retinal inner limiting membrane that separates the vitreous from the retina (Figs. $3 A, C, E$, arrowheads). In contrast, laminin $\alpha 2$ chain expression on embryonic day 8 is detected within the optic nerve (Fig. $3 B$, n) and retinal nerve fiber layer (Fig. $3 B, D, F$; arrow, nfl). Furthermore, many RGC bodies in paracentral retina (Fig. $3 F$; arrowhead, rgc) and peripheral retina (not shown) but not central retina (Fig. 3B,D; arrowhead, rgc) show intense laminin $\alpha 2$ chain immunoreactivity. In paracentral retina, weak anti- $\alpha 2$ labeling is also detected within the inner plexiform layer where RGC dendrites are located (Fig. 3F; small arrow, ipl). As RGC neurogenesis and differentiation spreads from the central region of the retina to the periphery starting on embryonic day 3 in chicks (Goldberg, 1974; Rager, 1980), it appears that laminin $\alpha 2$ chain expression is associated with differentiating RGCs. Similar results were obtained using retinal tissues derived from $6 \mathrm{~d}$ and $7 \mathrm{~d}$ chick embryos (not shown). No labeling of control tissue sections was observed upon incubation with normal rabbit serum or secondary antibody alone (not shown).

Figure 4 illustrates the distribution of laminin-1 and laminin $\alpha 2$ chain within the optic nerve, chiasm and tectum on embry- onic day 8 . Figure $4 A$ shows the location where the various photomicrographs were taken on tissue section diagrams across anterior (left) and posterior (right) optic tecta (t) and eyes (e). At this developmental stage, laminin $\alpha 2$ chain expression is detected within the optic nerves (Fig. $4 H, \mathrm{n}$ ), chiasm (Fig. $4 H$, c), and along the stratum opticum of the optic tectum where elongating RGC axons course prior to invading cellular tectal layers (Fig. 4D, arrowheads). A striking pattern of laminin $\alpha 2$ chain immunoreactivity is also observed within the posterior region of the optic tectum (Figs. $4 B, D$, open arrow). The orientation and location of such inner tectal laminin $\alpha 2$ chain expression suggest that it is associated with the tectobulbar fibers-the main efferent fibers of the optic tectum-which collect near the caudal end of the tectum to form the tectobulbar tract (Goldberg, 1974) (Fig. $4 B, D$, arrow). The tectobulbar fibers first appear across the entire tectal surface on embryonic day 3 (Goldberg, 1974). They become arranged in parallel rows, much like those immunoreactive for laminin $\alpha 2$ chain, between embryonic days 4 and 5 (Goldberg, 1974). Coincident with the wave of tectal differentiation (embryonic days 6-9), the tectobulbar fibers penetrate the tectal surface in an anteroposterior sequence to form the so-called stratum album centrale, a deep tectal layer located near the optic ventricle (LaVail and Cowan, 1971; Goldberg, 1974) (Fig. 4F, open arrow). Anti- $\alpha 2$ labeling of tectobulbar fibers and tract was also observed on $7 \mathrm{~d}$ embryonic tectal tissue (not shown). No labeling was detected in any of the above mentioned regions using polyclonal anti- $\alpha 1 \beta 1 \gamma 1$ (Fig. $4 C, E, G$ ), normal rabbit serum (not shown) or secondary antibody alone (not shown). Laminin-1 expression at this developmental stage is restricted to basement membranes such as the pial limiting membrane which lines the optic nerves (Fig. $4 G$, arrowheads).

Embryonic day 12. The expression of laminin $\alpha 2$ chain in various regions of the optic pathway on embryonic day 12 is 

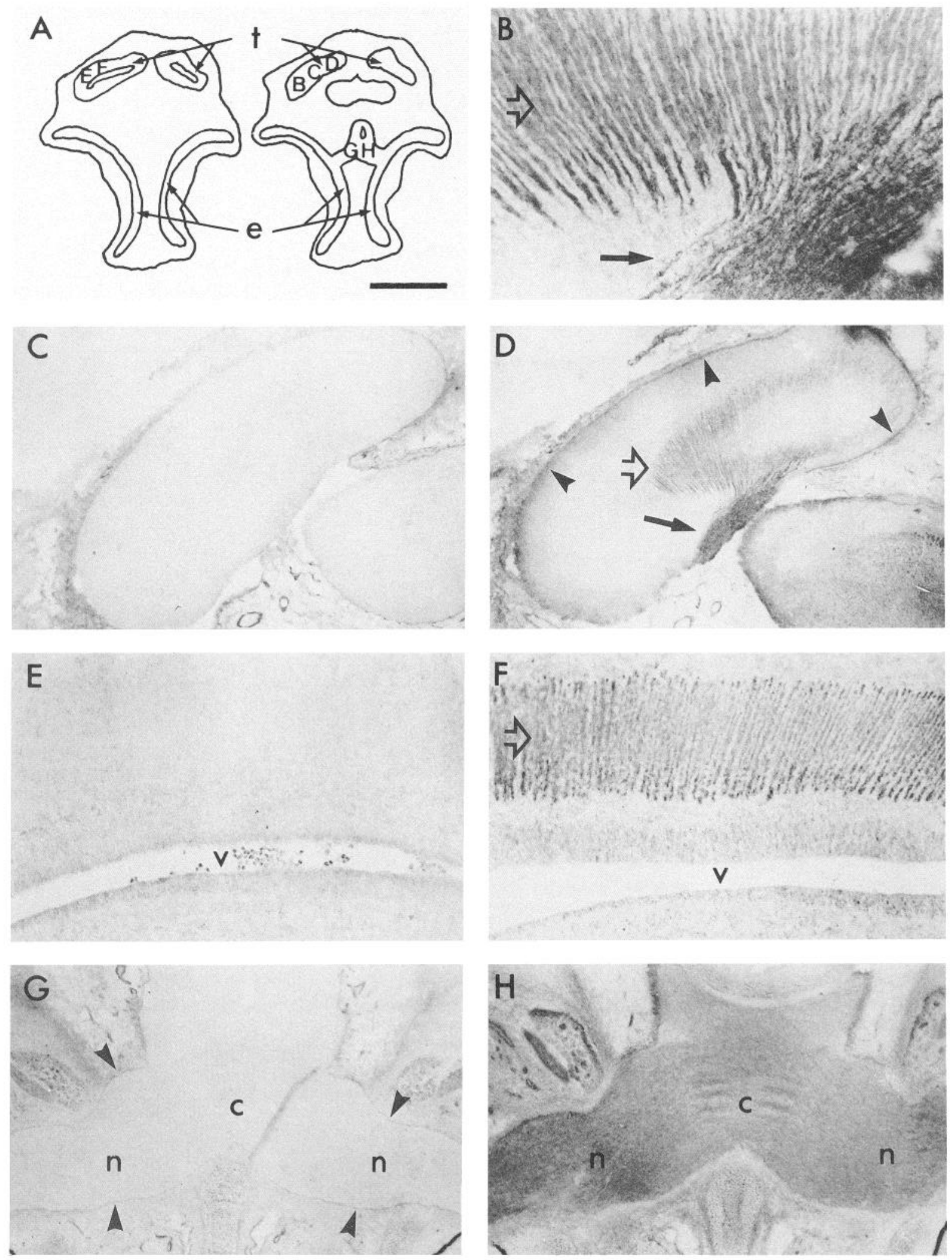

Figure. 4. Distribution of laminin-1 $(C, E, G)$ and laminin $\alpha 2$ chain $(B, D, F, H)$ along an $8 \mathrm{~d}$ embryonic chick optic pathway. $A$ shows the location where the various photomicrographs were taken on tissue section diagrams across anterior (left) and posterior (right) optic tecta $(t)$ and eyes (e). $B-D$ illustrate the caudal end of the optic tectum where the tectobulbar fibers (open arrow) collect to form the tectobulbar tract (arrow). In $D$, the arrowheads point to the stratum opticum of the optic tectum where RGC axons course prior to invading the superficial tectal layers. $E$ and $F$ illustrate an anterior region of the tectum where the tectal ventricule is easily observed. Finally, $G$ and $H$ provide views of the optic nerves and chiasm. Expression of laminin $\alpha 2$ chain was detected as in Figure 2 and is easily observed within the optic nerves $(H, n)$ and chiasm $(H, c)$. Moreover, laminin $\alpha 2$ chain expression is associated with the tectobulbar fibers (open arrow), tectobulbar tract (arrow), and stratum opticum of the tectum (arrowheads) as shown in $B, D$, and $F$. In contrast, laminin-1 expression is restricted to the external limiting membrane which surrounds 
shown in Figure 5. Figure $5 A$ shows the location where the various photomicrographs were taken on a tissue section diagram across optic tecta $(t)$ and eyes (e). At this developmental age, the retinal nerve fiber layer (Fig. $5 F, G$; arrows, nfl), optic tracts (Fig. 5E, o), anterior commissure (Fig. 5D,E, a) and stratum opticum of the optic tecta (Fig. 5C, arrowheads) express - laminin $\alpha 2$ chain. Laminin $\alpha 2$ chain immunoreactive lines running in parallel can be visualized at higher magnification within the optic tracts (Fig. 5B, arrowheads), anterior commissure (not shown) and along the stratum opticum of the optic tecta (not shown). In addition, laminin $\alpha 2$ chain expression is detected within the optic nerves (Fig. $5 D, G, \mathrm{n}$ ) and chiasm (Fig. $5 D, \mathrm{c}$ ), but expression is less than that observed on embryonic days 7 (not shown) and 8 (Figs. $3 B, 4 H ; \mathrm{n}$ and c). Many RGC bodies in peripheral retina (Fig. $5 F$; arrowhead, rgc) but not central retina (Fig. $5 G$, arrowheads) are labeled by polyclonal anti- $\alpha 2$, and a considerable variation in the intensity of labeling is noticeable among immunoreactive RGC bodies. Neurons in the retinal inner nuclear layer are also weakly labeled by polyclonal anti- $\alpha 2$ (Fig. $5 F$; small arrow, inl). Finally, no pattern of laminin $\alpha 2$ chain immunoreactivity reminiscent of tectobulbar fibers is observed within the optic tectum at this developmental stage (Fig. 5C). Laminin-1 expression is limited to basement membranes including the retinal inner limiting membrane and the pial membrane of the optic nerves, and is absent from RGC axonal pathway (not shown).

Adulthood. The distribution of laminin-1 and laminin $\alpha 2$ chain within the retina and optic nerve of an adult chicken is illustrated in Figure 6. Laminin $\alpha 2$ chain expression in adult retina is detected on what appears to be nonpigmented epithelial cells (Fig. $6 C$, small arrowheads). In addition, RGCs in adult retina are weakly laminin $\alpha 2$ chain immunoreactive (Fig. 6C; large arrowhcad, $\mathrm{rgc}$ ) as is the case for the adult optic nerve at nonbasal lamina sites (Fig. $6 \mathrm{D}, \mathrm{n}$ ). In comparison, laminin-1 expression in adult retinal tissue is confined to the inner limiting membrane (Fig. 6A, small arrowheads), and is absent from the ganglion cell layer (Fig. $6 A$; large arrowhead, rgc). Weak anti- $\alpha 1 \beta 1 \gamma 1$ immunoreactivity is nevertheless observed at non-basal lamina sites within the adult optic nerve (Fig. $6 B$, n). Similar findings were oblained using newborn chick tissues (embryonic day 20). No immunoreactivity was detected in control labeling experiments with secondary antibody alone (not shown).

Taken together, our immunohistochemical analyses of the developing chick optic pathway indicate that, in contrast to the $\alpha 1$, $\beta 1$, and $\gamma 1$ chains of laminin-1, laminin $\alpha 2$ chain is expressed within the pathway of avian RGCs during formation of the retino-tectal projections. Between embryonic days 5 and 12 , expression was detected along the retinal nerve fiber layer, optic nerves, chiasm, optic tracts, and stratum opticum of the tecta. Thereafter, laminin $\alpha 2$ chain expression is reduced in both retina and optic nerve but not abolished as evidenced by the low levels of anti- $\alpha 2$ immunoreactivity detected in adult retina and adult optic nerve.

\section{Developmental distribution of laminin-1 and laminin $\alpha 2$ chain in the mouse optic pathway}

In view of the extensive literature on the mammalian visual system including recent papers on $\mathrm{RGC}$ axon pathfinding at the optic chiasm (Sretavan, 1990; Sretavan and Reichardt, 1993; for a review, see Sretavan, 1993), we have next examined the developmental distribution of laminin $\alpha 2$ chain in the mouse optic pathway.

Embryonic day 13.5. By embryonic day 13.5 , the mouse retina has differentiated to form two neuroblastic layers and a marginal layer (Pei and Rhodin, 1970; Hinds and Hinds, 1974). The thick outer neuroblastic layer extends inwards from the ventricular surface and consists largely of the ovoid nuclei of radially oriented proliferative ventricular cells. The thin inner neuroblastic layer is more loosely organized and contains spherical RGC bodies and vitreal processes of ventricular cells. The marginal layer is found at the vitreal surface of the retina and consists of RGC axons and ventricular cell terminals. Pioneer RGC axons on embryonic day 13.5 have elongated toward the brain and reached the chiasm. The localization of laminin- 1 and laminin $\alpha 2$ chain within the eye and optic nerve of a $13.5 \mathrm{~d}$ mouse embryo is shown in Figure $7 A-D$. Laminin $\alpha 2$ chain expression at this developmental age is detected within the optic nerve (Fig. $7 B, D$; n) and along the retinal marginal layer (Fig. $7 B, D$; arrowheads), but is absent from the optic chiasm (Fig. $7 B, \mathrm{c}$ ). In comparison, laminin-1 expression is concentrated in basement membranes that line the optic nerve (Fig. $7 A, C$; arrows, n), chiasm (Fig. $7 A, C$; arrows, c), and retina (Fig. $7 A, C$; arrowheads). Also, the hyaloid-derived blood vessels located between the lens (le) and retina (r) show laminin $\alpha 2$ chain (Fig. $7 B, D$ ) and laminin-1 (Fig. $7 A, C)$ expression. The hyaloid vessels and their branches take up most of the space betwecn the neural retina and the lens during early embryonic development and form the so-called vascular tunic of the lens (Pei and Rhodin, 1970). No labeling was detected on mouse tissue sections incubated with normal rabbit serum or secondary antibody alone (not shown).

Embryonic day 17.5. The retina at this developmental stage shows signs of further differentiation; it is composed of an external limiting membrane, an outer neuroblastic layer, a transient fiber layer, a ganglion cell layer, a nerve fiber layer and an internal limiting membranc (Pci and Rhodin, 1970). The optic projections towards the brain are well established (Liesi and Silver, 1988). Also, the blood vessels which were quite dominant in the vitreous cavity on embryonic day 13.5 are now concentrated near the inner surface of the retina and around the lens as perilenticular vessels (Pei and Rhodin, 1970). The distribution of laminin-1 and laminin $\alpha 2$ chain expression within the eye, optic nerve, chiasm and optic tracts on embryonic day 17.5 is shown in Figure $7 E-J$. Intense laminin- 1 expression is detected in peripheral lens epithelium (Fig. $7 G, I$; le), in retinal neuroblastic layers (Fig. 7G,I; onb and inb), along the retinal inner limiting membrane (Fig. $7 I$, arrowheads) and along blood vessels that line the lens periphery and retinal inner margin (Fig. 7I, arrows). Similarly, the hyaloid artery near the optic nerve head (Fig. $7 \mathrm{H}$, arrowhead), the perilenticular blood vessels (Fig. $7 J$, arrows), an outermost epithelial layer of the lens periphery (Fig. $7 H, J$; le), the retinal neuroblastic layers (Fig. $7 H, J$; onb and inb) as well as the retinal marginal layer (Fig. $7 J$; arrowheads) express laminin $\alpha 2$ chain. Labeling of the optic nerve, chiasm and optic tracts using polyclonal anti- $\alpha 1 \beta 1 \gamma 1$ is restricted to the surrounding pial basement membrane (Fig. $7 E$, arrows). In comparison,

$\leftarrow$

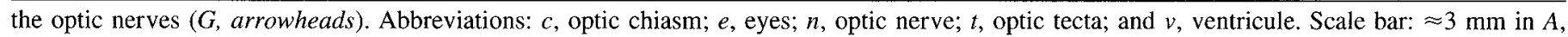
$\approx 75 \mu \mathrm{m}$ in $B, \approx 300 \mu \mathrm{m}$ in $C, D, G$, and $H$, and $\approx 100 \mu \mathrm{m}$ in $E$ and $F$. 
A
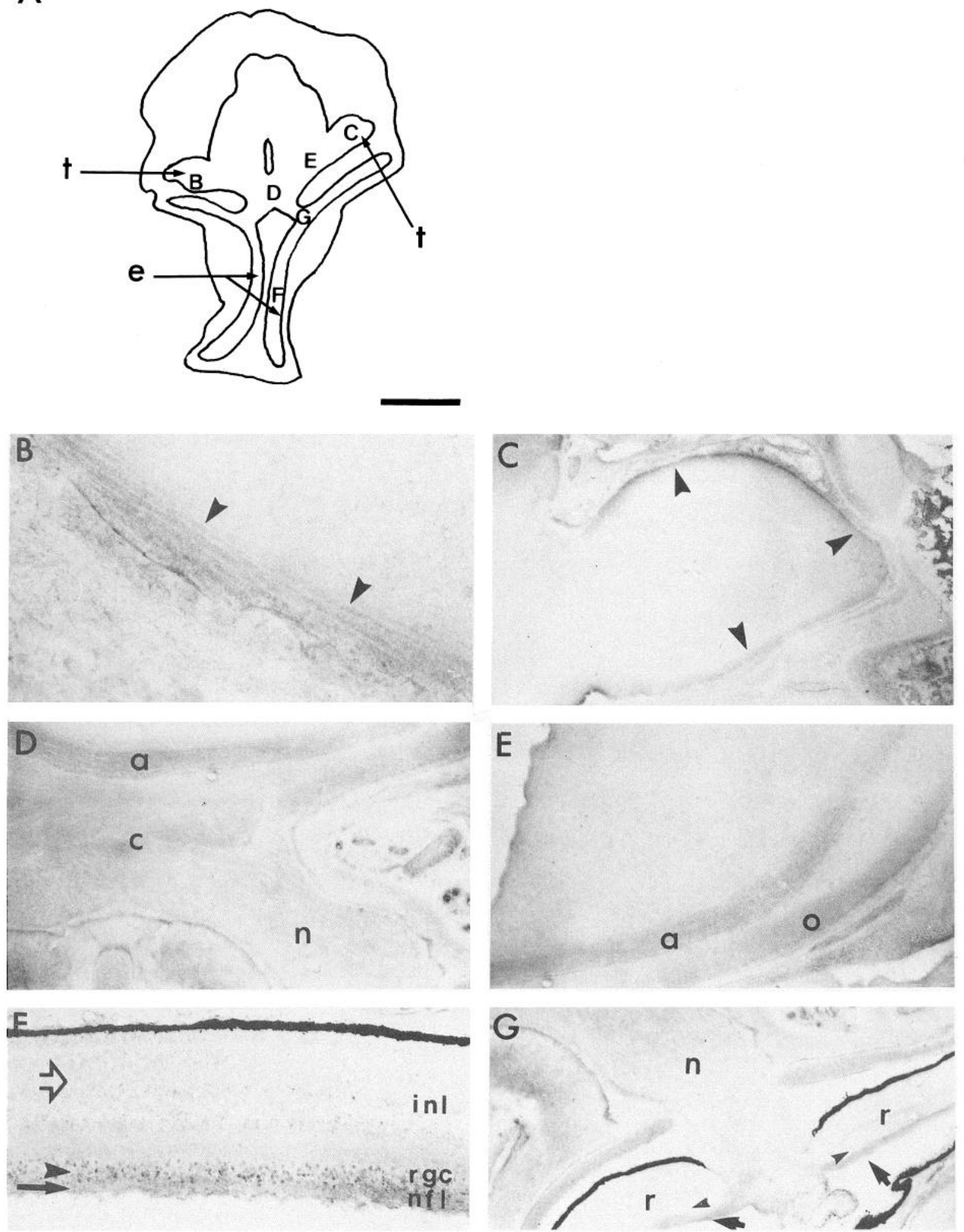

Figure 5. Distribution of laminin $\alpha 2$ chain along an $12 \mathrm{~d}$ embryonic chick optic pathway. $A$ displays the location where the various photomicrographs were taken on a tissue section diagram across optic tecta $(t)$ and eyes $(e)$. The optic tract near tectum, optic tectum, optic chiasm, optic tract near chiasm, peripheral retina, and optic nerve near retina are illustrated in $B-G$, respectively. Expression of laminin $\alpha 2$ chain was detected as in Figure 2 and is easily observed within the retinal nerve fiber layer $(F$ and $G$; arrows), anterior commissure $(D$ and $E ; a)$, optic tract $(D$ and $E ; o)$ and stratum opticum of the tectum ( $C$, arrowheads). Laminin $\alpha 2$ chain immunoreactive lines running in parallel can be visualized at higher magnification within the optic tracts $(B$, arrowheads). In contrast, weak anti- $\alpha 2$ reactivity is associated with the optic nerves $(D$ and $G$; $n)$, chiasm $(D, c)$, RGC layer $(F$, arrowhead $)$ and retinal inner nuclear layer $(F$, open arrow). Abbreviations: $a$, anterior commissure; $c$, optic chiasm; $e$, eyes; $i n l$, inner nuclear layer; $n$, optic nerve; $n f l$, nerve fiber layer; $o$, optic tract; $r$, retina; $r g c$, retinal ganglion cell layer; and $t$, optic tecta. Scale bar represents $\approx 3 \mathrm{~mm}$ in $A, \approx 120 \mu \mathrm{m}$ in $B, \approx 300 \mu \mathrm{m}$ in $C-E$ and $G$, and $\approx 100 \mu \mathrm{m}$ in $F$. 

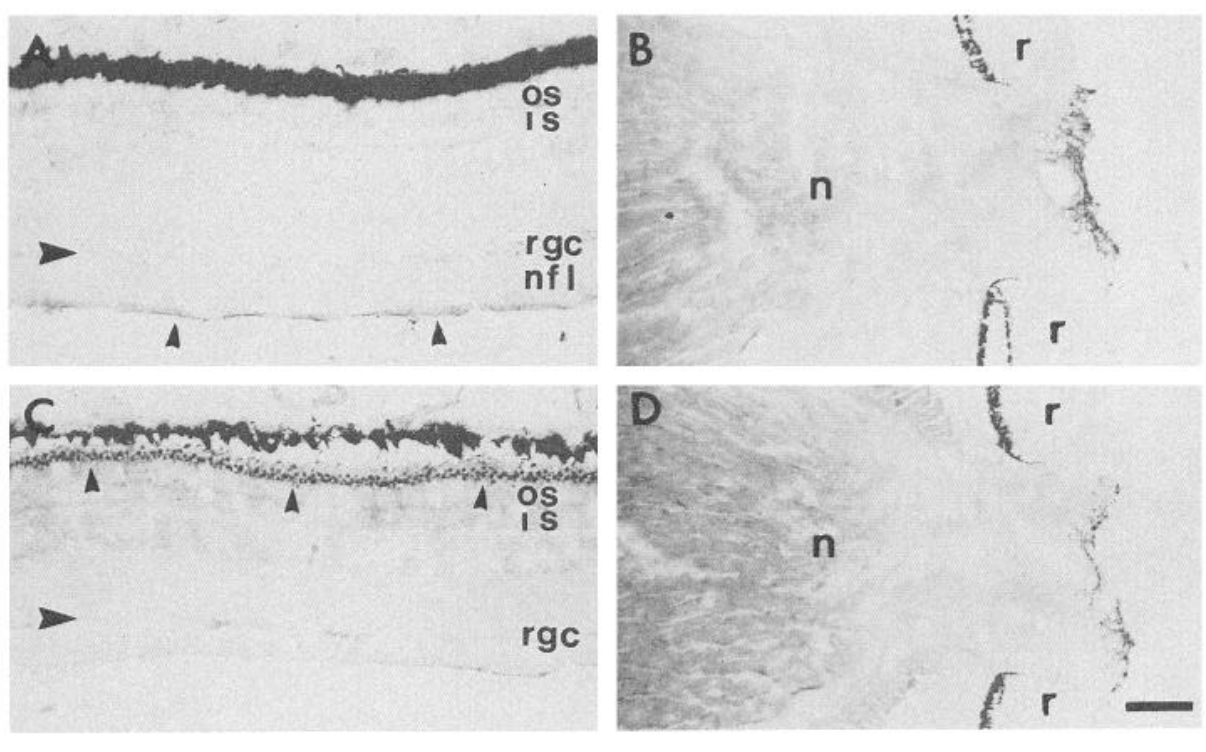

Figure 6. Distribution of laminin-1 and laminin $\alpha 2$ chain within retina $(A$, $C)$ and optic nerve $(B, D)$ of an adult chicken. Laminin-1 expression in adult retina is limited to the inner limiting membrane $(A$, small arrowheads) and is absent from the RGC layer ( $A$, large arrowhead). In comparison, laminin $\alpha 2$ chain expression is associated with nonpigmented epithelial cells $(C$, small arrowheads) and with RGCs ( $C$, large arrowhead) in adult retina. In addition, polyclonal anti- $\alpha 1 \beta 1 \gamma 1$ and polyclonal anti- $\alpha 2$ label the adult optic nerves at non-basal lamina sites $(B, D ; n)$. Abbreviations: $i s$, photoreceptor cell inner segments; $n$, optic nerve; $n f l$, nerve fiber layer; os, photoreceptor cell outer segments; $r$, retina; and $r g c$, retinal ganglion cell layer. Scale bar represents $\approx 80 \mu \mathrm{m}$ in $A, C$ and $E$, and $\approx 200 \mu \mathrm{m}$ in $B, D$ and $F$. weak laminin $\alpha 2$ chain immunolabeling is found within the optic nerves (Fig. $7 F, \mathrm{n}$ ), chiasm (Fig. $7 F, \mathrm{c}$ ), and along the optic tracts (Fig. $7 F$, arrowheads). No labeling of mouse tissue sections was observed at this developmental stage using control antibodies (not shown).

Postnatal day 4. The layered structure of mouse retina on postnatal day 4 is similar to that on embryonic day 17.5 (Blanks, 1981). The distribution of laminin-1 and laminin $\alpha 2$ chain in 4 d postnatal mouse retina is shown in Figure $8, A$ and $B$. At this developmental stage, the inner limiting membrane (Fig. $8 A$, small arrowheads) and RGCs (Fig. $8 A$; black arrow, rgc) are laminin-1 immunoreactive; laminin $\alpha 2$ chain expression is detected on RGCs (Fig. $8 B$; black arrow, rgc) and along the retinal nerve fiber layer (Fig. $8 B$; white arrow, nfl). In contrast, little reactivity is detected within the outer neuroblastic layer using either polyclonal anti- $\alpha 2$ or polyclonal anti- $\alpha 1 \beta 1 \gamma 1$ (Fig. $8 A, B$; open arrow, onb). Labeling of tissue sections with normal rabbit serum or secondary antibody alone yielded no significant reactivity (not shown).

Adulthood. Retinal cell differentiation in mouse is mainly a postnatal event which is completed on postnatal day 14 at the time of eyelids opening (Blanks, 1981). The fully differentiated retina is composed of an external limiting membrane, an outer nuclear layer, an outer plexiform layer, an inner nuclear layer, an inner plexiform layer, a ganglion cell layer, a nerve fiber layer, and an internal limiting membrane (Blanks, 1981). The expression of laminin- 1 and laminin $\alpha 2$ chain within the retina and optic nerve of an adult chicken is illustrated in Figure $8 C$ $F$. Laminin-1 expression in adult retina is detected on RGC bodies (Fig. 8E; arrowheads, rgc), and along the retinal inner limiting membrane (Fig. $8 E$, arrows), retinal blood vessels (Fig. $8 E$, small arrows) and pial membrane of the optic nerve (Fig. $8 C$, arrows). Weak nonbasal labeling of the adult optic nerve is also observed using polyclonal anti- $\alpha 1 \beta 1 \gamma 1$ (Fig. $8 C$, n). In comparison, laminin $\alpha 2$ chain is expressed in the adult optic nerve at both basal (Fig. 8D, arrows) and nonbasal lamina sites (Fig. $8 D, \mathrm{n})$. Weak anti- $\alpha 2$ labeling is also detected on RGC bodies (Fig. $8 F$; small arrowheads, rgc) but none is found to associate with the retinal nerve fiber layer (Fig. $8 F$, arrows). No labeling was observed in control tissue sections incubated with normal rabbit serum or secondary antibody alone (not shown).
Overall, during formation of chick and mouse retinal projections to the brain, laminin-1 expression is detected along the pial limiting membrane that surrounds the optic nerves and along the retinal inner limiting membrane. The peripheral lens epithelium, the hyaloid-derived blood vessels and ganglion cell bodies also express laminin-1 in developing mouse eye tissues. The chick retina is avascular and no laminin-1 expression is associated with embryonic ganglion cell bodies. In comparison, laminin $\alpha 2$ chain is expressed within the retinal ganglion cell layer, retinal nerve fiber layer, optic nerves and chiasm in chick and mouse tissues, at developmental times consistent with a growth-promoting role for laminin $\alpha 2$ chain in vivo. Laminin $\alpha 2$ chain expression was also demonstrated along the chick optic tracts and stratum opticum of the optic tecta, and within the developing chick tectobulbar pathway. In mouse tissues, the peripheral lens epithelium and the hyaloid-derived blood vessels also express laminin $\alpha 2$ chain during embryonic development. The reported spatiotemporal distribution of laminin $\alpha 2$ chain in developing chick and mouse optic pathways suggests that a laminin complex comprising an $\alpha 2$ chain, a $\beta$ chain other than $\beta 1$ and a $\gamma$ chain other than $\gamma 1$ may serve as an adhesive substrate for elongating RGC growth cones. In addition, expression of laminin $\alpha 2$ chain along chick and mouse RGC axonal pathway is shown to be reduced but maintained following formation of retinal projections to the brain; expression is detected at nonbasal lamina sites within the adult optic nerves and on RGC bodies in adult retina. Laminin-1 is also weakly expressed at nonbasal lamina sites within the adult chick and mouse optic nerves. These results suggest that a laminin complex comprising an $\alpha 2$ chain, a $\beta 1$ chain, and/or a $\gamma 1$ chain is likely to be expressed in late developing optic nerve.

\section{Optic nerve-derived type-1 astrocytes express laminin $\alpha 2$ chain on their surface}

Astrocytes in culture and glial-like cell lines have previously been reported to express laminin-1 and/or laminin $\beta 2$ chain (slaminin) on their surface (Liesi et al., 1983; McLoon et al., 1988; Chiu et al., 1991; Green et al., 1992; Hunter et al., 1992a). As a first step in identifying a cellular source of laminin $\alpha 2$ chain along RGC axonal pathway, glial cell cultures from $8 \mathrm{~d}, 12 \mathrm{~d}$, and $15 \mathrm{~d}$ embryonic chick optic nerves were prepared as de- 

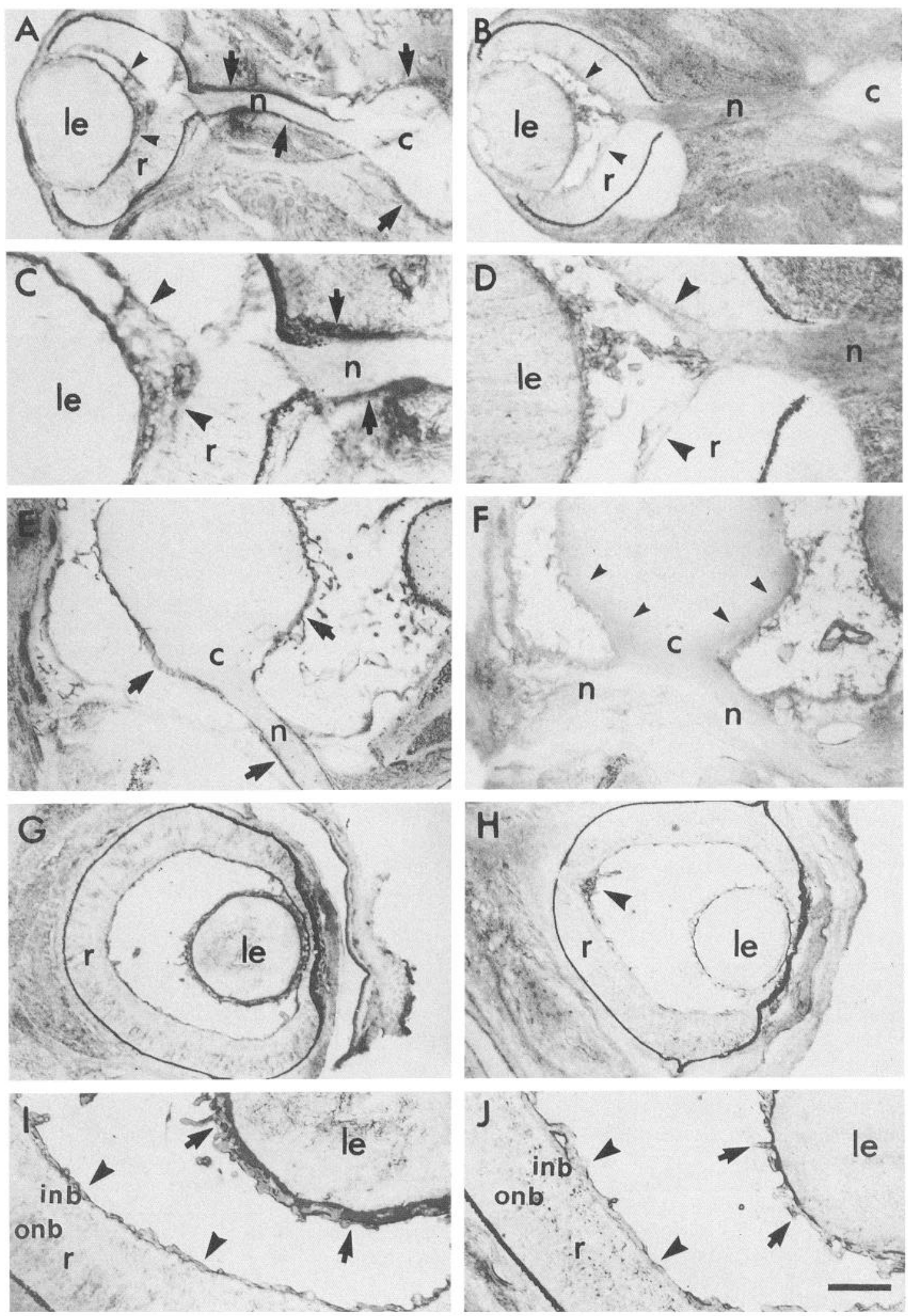

Figure 7. Distribution of laminin-1 $(A, C, E, G, I)$ and laminin $\alpha 2$ chain $(B, D, F, H, J)$ along $13.5 \mathrm{~d}(A-D)$ and $17.5 \mathrm{~d}(E-J)$ embryonic mouse optic pathways. $C$ and $D$ are magnified views of $A$ and $B$, respectively; $I$ and $J$ are magnified views of $G$ and $H$, respectively. On embryonic day 13.5, laminin $\alpha 2$ chain is detected within the optic nerves $(B$ and $D ; n)$, along the retinal marginal layer where RGC axons are located $(B$ and $D$; arrowheads) and on hyaloid-derived blood vessels that fill-in the space separating the lens from the retina $(B$ and $D$; le, $r)$. On embryonic day 17.5 , weak laminin $\alpha 2$ chain expression is apparent within the optic nerves $(F, n)$, retinal marginal layer $(J$, arrowheads) and retinal neuroblastic layers $(J, r)$. The hyaloid artery located near the optic nerve head $(H$, arrowhead $)$ as well as the peripheral lens epithelium and hyaloid-derived vessels surrounding the lens ( $J$, arrows) are also labeled by polyclonal anti- $\alpha 2$ at this developmental stage. In comparison, laminin-1 expression at $13.5 \mathrm{~d}$ and $17.5 \mathrm{~d}$ is concentrated on hyaloid-derived blood vessels located between the lens and retina $(I$, arrows; and $C)$, and is associated with basement membranes that line the optic nerves $(A, C, E$; arrows $)$ and retina $(A, C, I$; arrowheads). Polyclonal anti- $\alpha 1 \beta 1 \gamma 1$ also labels the retinal 
scribed in the Material and Methods section. Over $95 \%$ of cells in such cultures were found to express glial fibrillary acidic protein, a specific astrocyte marker, after $3-4 \mathrm{~d}$ in vitro (Fig. 9A) (Raff et al., 1979). Astrocytes are mainly of two types. Type-1 astrocytes are large and flat polygonal cells; they have been reported to primarily differentiate in glial cell culture derived from immature optic nerve (Raff et al., 1983; McLoon et al., 1988). In contrast, type- 2 astrocytes have a neuron-like morphology and are major components of the mature nerve (Raff et al., 1983; McI oon et al., 1988). In accordance with these findings, few cells $(<5 \%)$ in our glial cell cultures were labeled by monoclonal A2B5 (Eisenbarth et al., 1979), a marker of type-2 astrocytes and oligodendrocytes that both differentiate from A2B5-positive O-2A precursor cells (Raff and Miller, 1984) (Fig. 9C,D).

The presence of laminin $\alpha 2$ chain in primary glial cell cultures was first investigated by Western blot analysis using polyclonal anti- $\alpha 2$. A major band of $\approx 380 \mathrm{kDa}$ (nonreduced; Fig. $9 H$, lane 2 ) or $\approx 300 \mathrm{kDa}$ (reduced; not shown) is shown to react with polyclonal anti- $\alpha 2$ in extract of cultured glial cells prepared from $15 \mathrm{~d}$ chick optic nerves. Similar results were obtained using cultured glial cells prepared from $12 \mathrm{~d}$ chick optic nerves (not shown). These findings are identical to immunoblotting results obtained using extracts of embryonic chick eyes (Fig. 1D) and postnatal mouse cycs (Fig. 1C), and indicate the presence of laminin $\alpha 2$ chains in chick optic nerve-derived glial cell cultures.

Immunofluorescence staining confirmed the presence of laminin $\alpha 2$ chain in chick optic nerve derived-glial cell cultures. Polyclonal anti- $\alpha 2$ detects extracellular fibrils on the surface of a majority $(>95 \%)$ of cultured glial cells, whose morphology resembles that of cultured type-1 astrocyles (Fig. $9 F$, arrowheads; Figs. 9B,E,G). Occasionally, anti- $\alpha 2$ immunoreactivity was detected as pericellular matrix deposits surrounding cultured type-1 astrocytes (Fig. 9B,G; arrows). Live astrocytes (Fig. 9B) stained similarly as fixed and unpermeabilized cells (Figs. 9E$G$ ), thus confirming the extracellular nature of laminin $\alpha 2$ chain deposits on type- 1 astrocytes. In fact, permeabilization of astrocyte surface using detergent $(0.1 \%$ Triton-X) resulted in loss of the laminin $\alpha 2$ chain immunoreactivity (not shown). These data strongly suggest that laminin $\alpha 2$ chain is synthesized and se creted by type- 1 astrocytes in developing optic nerves. Comparable results were obtained using glial cultures derived from $8 \mathrm{~d}, 12 \mathrm{~d}$, or $15 \mathrm{~d}$ embryonic chick optic nerves. In double labeling experiments using monoclonal antibody A2B5 and polyclonal anti- $\alpha 2$, no laminin $\alpha 2$ chain immunoreactivity was detected on type- 2 astrocytes present in glial cultures prepared from $12 \mathrm{~d}$ chick optic nerves (not shown).

\section{Cultured chick retinal neurons express laminin $\alpha 2$ chain on their surface}

As revealed by our immunohistochemical analyses, laminin $\alpha 2$ chain expression is detected on avian and murine RGCs at various developmental stages (Fig. $3 F$, arrowhead; Fig. $5 F$, arrowhead; Fig. $8 B$, black arrow). Several groups have similarly reported neuronal laminin-like expression throughout the CNS (Liesi, 1983; Yamamoto et al., 1988; Hagg et al., 1989; Suzuki et al., 1990; Zhou, 1990; Jucker et al., 1993b). However, others failed to detect laminin expression on neurons (Liesi et al., 1984; Liesi, 1985; Eriksdotter-Nilsson et al., 1986; Letourneau et al., 1988; Liesi and Silver, 1988; Hunter et al., 1992a). To determine whether or not retinal neurons may synthesize and express laminin $\alpha 2$ chain, epithelia-free primary neuronal cultures were prepared from $7 \mathrm{~d}$ chick retinae (Fig. 10A; see Material and Methods section for details). Cultures were first examined by Western blot analysis for the presence of laminin $\alpha 2$ chain using polyclonal anti- $\alpha 2$. Polyclonal anti- $\alpha 2$ recognizes a single faint band of $\approx 380 \mathrm{kDa}$ in nonreduced extracts of primary retinal cell cultures derived from $7 \mathrm{~d}$ chick embryos (not shown). Moreover, polyclonal anti- $\alpha 2$ labels rather weakly a subpopulation of cultured chick retinal neurons (not shown).

In order to clearly demonstrate laminin $\alpha 2$ chain expression on the surface of cultured chick retinal neurons, ascites fluid containing monoclonal anti- $\alpha 2$ was used (MAB 1922; Chemicon International). Similarly to polyclonal anti- $\alpha 2$, monoclonal anti$\alpha 2$ recognizes $\mathrm{a} \approx 70 \mathrm{kDa}$ (nonreduced) or $\mathrm{a} \approx 80 \mathrm{kDa}$ (reduced) polypeptide in purified human placental merosin (Leivo and Engvall, 1988). Monoclonal anti- $\alpha 2$ also labels the developing chick optic pathway in a manner very similar to that of polyclonal anti- $\alpha 2$ (not shown) and recognizes $a \approx 380 \mathrm{kDa}$ polypeptide in nonreduced extracts of epithelia-free primary neuronal cultures prepared from $7 \mathrm{~d}$ chick retinac (Fig. 10B, arrow). Monoclonal anti- $\alpha 2$ detects laminin $\alpha 2$ chain expression on the surface of a subpopulation of live (Fig. 10C, arrows) and fixed but unpermeabilized (Fig. 10D, arrows) retinal neurons in primary retinal cell cultures. To show specific laminin $\alpha 2$ chain expression by RGCs, we purified $7 \mathrm{~d}$ embryonic chick RGCs by antibody-mediated adhesion using a monoclonal antibody against chick Thy.1 (Lehwalder et al., 1989; see the Materials and Methods section for details). As illustrated in Figure 11, monoclonal anti- $\alpha 2$ detects laminin $\alpha 2$ chain expression on the cell body (Fig. $11 B, C$ ), neuritic processes (Fig. $11 B-D$; small arrows) and growth cone (Fig. $11 D$, large arrow) of live (Fig. $11 B$ ) and fixed but unpermeabilized (Fig. $11 C, D$ ) cultured chick RGCs. Non-RGC retinal neurons in primary cultures are likely to also express laminin $\alpha 2$ chain on their surface. Immunohistochemical evidence that developing retinal neurons other than RGCs may express laminin $\alpha 2$ chain was presented earlier: lam. inin $\alpha 2$ chain was detected in the inner nuclear layer of a $12 \mathrm{~d}$ embryonic chick retina (Fig. $5 F$; open arrow, inl) and in the outer neuroblastic layer of a $17.5 \mathrm{~d}$ embryonic mouse retina (Fig. $7 J$, onb) where non-RGC retinal neurons (amacrine, horizontal, and bipolar cells) develop.

\section{Discussion}

In the present study, we have examined by light microscope immunohistochemistry the expression of laminin $\alpha 2$ chain within the developing chick and mouse optic pathways. We report that, in contrast to the $\alpha 1, \beta 1$, and $\gamma 1$ chains of laminin-1, laminin $\alpha 2$ chain is expressed in the pathway of elongating avian and murine RGC axons during formation of retinal projections to the brain and that low levels of expression are detected thereafter and up to adulthood. In addition, cell culture data suggest that type- 1 astrocytes in developing optic nerves and embryonic RGCs may synthesize laminin $\alpha 2$ chains in vivo. Finally, we

$\leftarrow$

neuroblastic layers on embryonic day $17.5(G, r)$. Abbreviations: in $b$, inner neuroblastic layer; $l e$, lens; $c$, optic chiasm; $n$, optic nerve; $o$, optic tract; onb, outer neuroblastic layer; and $r$, retina. Scale bar represents $\approx 200 \mu \mathrm{m}$ in $A$ and $B, \approx 80 \mu \mathrm{m}$ in $C$ and $D$, $\approx 250 \mu \mathrm{m}$ in $E-H$, and $\approx 100$ $\mu \mathrm{m}$ in $I$ and $J$. 
Figure 8. Distribution of laminin-1 and laminin $\alpha 2$ chain within a 4 d postnatal mouse eye $(A, B)$, adult mouse retina $(C-F)$, and adult optic nerve $(E$, $F)$. Laminin-1 $(A, C, E)$ and laminin $\alpha 2$ chain $(B, D, F)$ expression were detected as in Figure 2. RGCs $(A, B$, black arrow; $E, F$, arrowheads), the pial basement membrane $(C, D$; ar rows), the inside of the optic nerve ( $C$, $D ; n)$ and muscle fibers $(C, D ; m)$ are all labeled by polyclonal anti- $\alpha 2$ and polyclonal anti- $\alpha 1 \beta 1 \gamma 1$ in $4 \mathrm{~d}$ postnatal and adult tissues. In addition, polyclonal anti- $\alpha 1 \beta 1 \gamma 1$ labels the retinal inner limiting membrane $(A$, arrowheads; $E$, arrows) and retinal blood vessels $(E$, small arrows). In comparison, polyclonal anti- $\alpha 2$ labels the retinal nerve fiber layer in $4 \mathrm{~d}$ postnatal retina $(B$, white arrow) but not in adult retina $(F$, arrows). Finally, no reactivity is detected within the ventricular layer in $4 \mathrm{~d}$ postnatal retina ( $A, B$; open arrow). Abbreviations: $n$, optic nerve; $m$, muscle; $n f l$, nerve fiber layer; onl, outer nuclear layer; opl, outer plexiform layer; onb, outer neuroblastic layer; $r$, retina; and $r g c$, retinal ganglion cell layer. Scale bar represents $\approx 80 \mu \mathrm{m}$ in $A$ and $B, \approx 200 \mu \mathrm{m}$ in $C$ and $D$, and $\approx 130 \mu \mathrm{m}$ in $E$ and $F$.
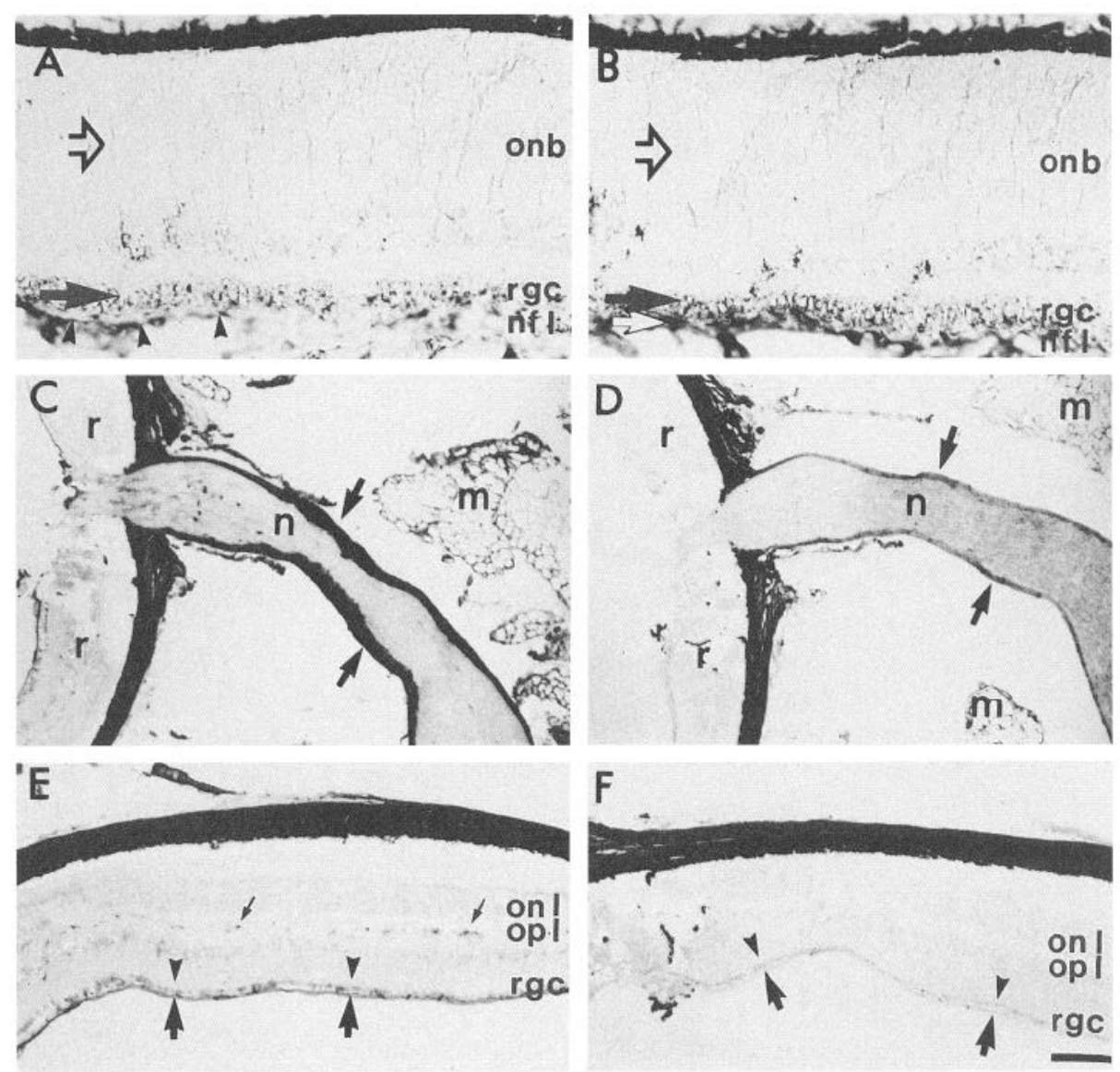

show that laminin $\alpha 2$ chain, in contrast to laminin-1, is also highly expressed in the developing chick tectobulbar pathway.

\section{Laminin complex in RGC axonal pathway}

Similarly to earlier studies (Cohen et al., 1987; Liesi et al., 1988), expression of laminin-1 was not detected in the pathway of elongating chick and mouse RGC growth cones at developmental times consistent with a growth-promoting role in vivo. In contrast, the reported spatiotemporal distribution of laminin $\alpha 2$ chain in developing chick and mouse optic pathways suggests that a laminin complex comprising an $\alpha 2$ chain, a $\beta$ chain other than $\beta 1$ and a $\gamma$ chain other than $\gamma 1$ may serve as an in vivo adhesive substrate for elongating RGC growth cones. To date, three $\alpha$, three $\beta$, and two $\gamma$ laminin chain variants have been reported to assemble into distinct laminin-like trimeric complexes (reviews, Tryggvason, 1993; Burgeson et al., 1994). Expression in the developing optic pathway of $\beta$ chains other than $\beta 1$ and of $\gamma$ chains other than $\gamma 1$ has however not yet been reported. Both laminin-1 and laminin $\alpha 2$ chain were detected at nonbasal lamina sites within the adult optic nerves. These findings are consistent with results by McLoon et al. (1988) which indicate that a variant laminin complex comprising a non- $\alpha 1$ chain, a $\beta 1$ chain and/or a $\gamma 1$ chain is expressed in late developing optic nerve.

Laminins are believed to function as heterotrimers. It will therefore be important in the future to determine the chain composition of the potential heterotrimer(s) containing the laminin $\alpha 2$ chain in RGC axonal pathway. However, as suggested by Hunter et al. (1992b) for the expression of the laminin $\beta 2$ chain (s-laminin) in rod interphotoreceptor matrix, laminin $\alpha 2$ chain could form a complex with nonlaminin molecules or exist as a monomer along the developing optic pathway. Several studies suggest that a laminin heterotrimer may not be required for biological activity. For example, Wujek et al. (1990) have demonstrated that the ECM of cultured cortical astrocytes only comprises the $\gamma 1$ chain of laminin-1. As anti-laminin-1 antibodies inhibit the neurite outgrowth of pheochromocytoma (PC12) cells on such astrocytic ECM, their results suggest that the $\gamma 1$ chain of laminin-1 is sufficient to induce neurite outgrowth. In addition, recombinant netrin- 1 and recombinant netrin- 2 were recently shown to promote axonal outgrowth by $13 \mathrm{~d}$ embryonic rat dorsal spinal cord explants (Serafini et al., 1994). Netrin-1 and netrin-2 are laminin-related proteins and vertebrate homologs of the C. elegans protein UNC-6 (Serafini et al., 1994). Their N-terminal two-thirds are homologous to the N-termini of the $\alpha 1, \beta 1$, and $\gamma 1$ chains of laminin-1 (Ishii et al., 1992; Serafini et al., 1994). Also, recombinant fragments of the laminin $\beta 2$ chain (s-laminin) were reported to mediate neuronal adhesion (Hunter et al., 1989; Hunter et al., 1991).

\section{Laminin receptors on developing $R G C s$}

Elongating RGC growth cones are likely to use integrin receptors to interact with laminin $\alpha 2$ chain. Retinal neurons have been reported to express $\alpha 3 \beta 1$ and $\alpha 6 \beta 1$ integrin heterodimers which function as laminin-binding proteins on a variety of neural cells (Tawil et al., 1990; Cohen and Johnson, 1991; Engvall et al., 1992; Tomaselli et al., 1993; reviews, Reichardt and Tomaselli, 1991; Reichardt et al., 1992). Interestingly, embryonic avian RGCs also express a novel integrin heterodimer, $\alpha 8 \beta 1$ (Bossy et al., 1991). $\alpha 8$ integrin immunoreactivity was detected in the 

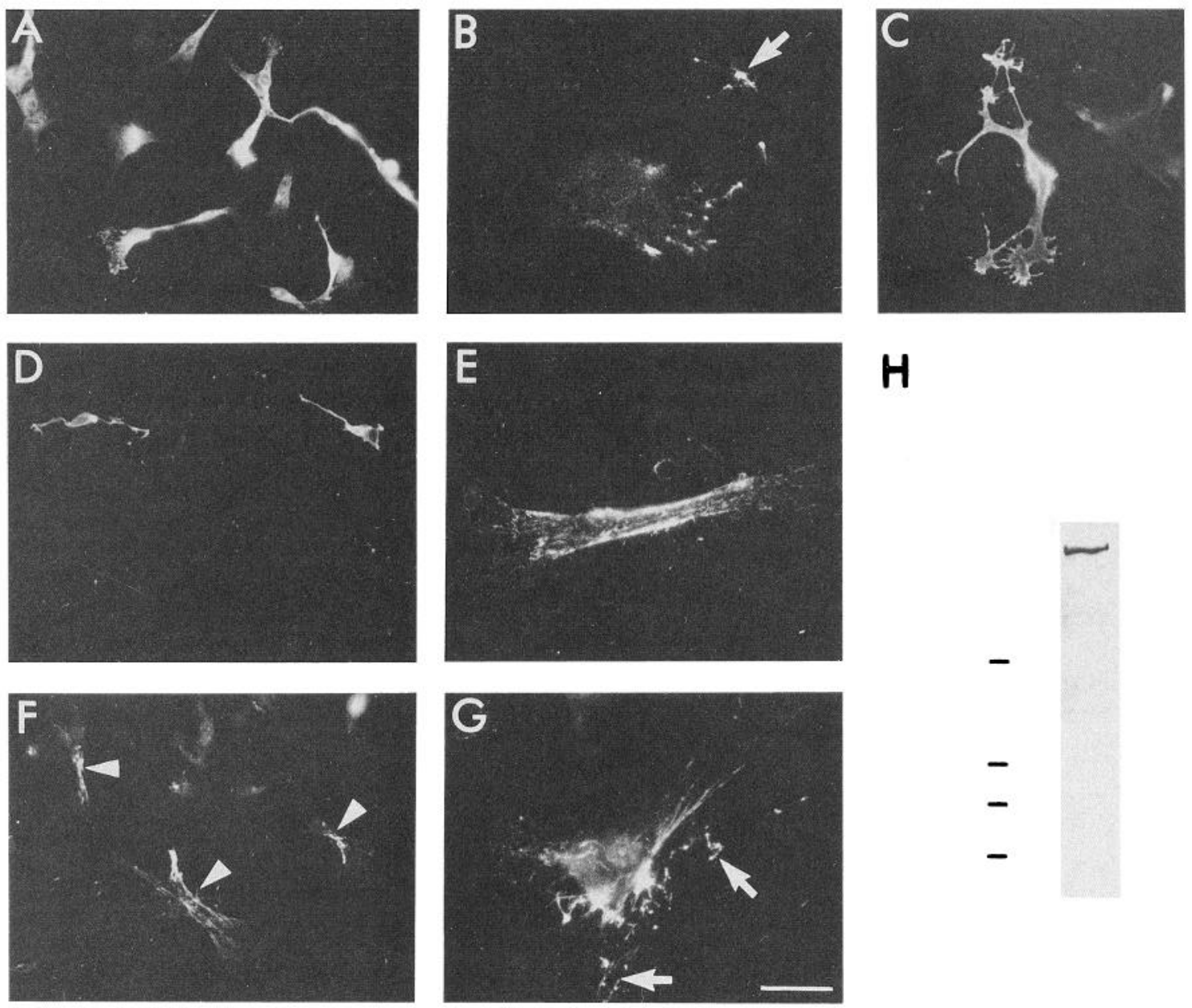

Figure 9. Expression of laminin $\alpha 2$ chain in glial cell cultures derived from chick optic nerves. Glial cell cultures were prepared from $8 \mathrm{~d}(B)$ or $15 \mathrm{~d}(A, C, D-G)$ chick optic nerves and processed for immunohistochemistry and immunoblotting as described in the Materials and Methods section. $A$ illustrates the labeling of cultured glial cells using polyclonal anti-GFAP, an astrocytic marker. Few cultured cells were labeled by monoclonal A2B5, a marker of type-2 astrocytes, oligodendrocytes and O-2A precursor cells $(C, D)$. Expression of laminin $\alpha 2$ chain on both live $(B)$ and fixed but unpermeabilized cells $(E-G)$ was examined using polyclonal anti- $\alpha 2$. A great proportion $(>95 \%)$ of astrocytes in culture whose morphology resemble that of type-1 astrocytes were found to express laminin $\alpha 2$ chain as extracellular fibrils on their surface $(B, E-G)$ and occasionally as pericellular deposits $(B, G$; arrows). Polyclonal anti- $\alpha 2$ recognizes a $\approx 300 \mathrm{kDa}$ (reduced; not shown) or a $\approx 380 \mathrm{kDa}(H$, lane 2 ; nonreduced ) polypeptide in extract of cultured glial cells. Molecular weight markers in $H$ correspond to $200 \mathrm{kDa}, 116 \mathrm{kDa}, 97 \mathrm{kDa}$, and $65 \mathrm{kDa}$. Scale bar represents $\approx 50 \mu \mathrm{m}$ in $A, D$, and $F$ and $\approx 20 \mu \mathrm{m}$ in $B, C, E$, and $G$.

chick RGC projection pathway-from retina to optic tectumin a pattern closely resembling that reported here for laminin $\alpha 2$ chain (Bossy et al., 1991). Thus, laminin $\alpha 2$ chain may serve as a ligand for the $\alpha 8 \beta 1$ heterodimer. So far, the $\alpha 8 \beta 1$ integrin has been shown to mediate interactions of embryonic chick sensory and motor neurons with tenascin-C (Varnum-Finney et al., 1995).

\section{Cellular sources of laminin $\alpha 2$ chain along $R G C$ axonal pathway}

Cultured astrocytes have been reported to synthesize the laminin $\beta 2$ chain (s-laminin) and the laminin $\gamma 1$ chain but not the laminin $\alpha 1$ or $\beta 1$ chains (Wujek et al., 1990; Hunter et al., 1992a). Reactive glial cells and glial-like cell lines accumulate laminin-1 and/or laminin $\beta 2$ chain intracellularly or in culture medium (Liesi et al., 1984; Hagg et al., 1989; Chiu et al., 1991; Green et al., 1992; Jucker et al., 1993a). Recently, laminin $\alpha 2$ chain was shown to be a component of the neurite-promoting factor secreted by RN22 Schwannoma cells (Engvall et al., 1992). In this study, we report that optic nerve-derived type-1 astrocytes in culture express laminin $\alpha 2$ chains as extracellular fibrils on their surface. In view of previous findings, type-1 astrocytes could synthesize the laminin complex $\alpha 2 \beta 2 \gamma 1$, but this remains to be shown.

The expression of laminin $\alpha 2$ chain by type- 1 astrocytes, however, cannot alone explain the immunoreactivity detected in early developing optic nerve. In rat optic nerve, type-1 astrocytes differentiate around embryonic day 16 (Raff and Miller, 1984). Corresponding development in mouse optic nerve occurs at very similar times, and after embryonic day 13.5 when laminin $\alpha 2$ chain expression was detected (Pei and Rhodin, 1970) (Fig. $6 B, D$ ). This suggests that other cells, possibly optic stalk neuroepithelial cells, are synthesizing laminin $\alpha 2$ chain during early development. In addition, laminin $\alpha 2$ chain expression was detected at nonbasal lamina sites within the adult chick and mouse optic nerves, suggesting that type- 2 astrocytes which are major components of the mature optic nerve may also synthesize laminin $\alpha 2$ chains. We found no evidence for expression of lam- 


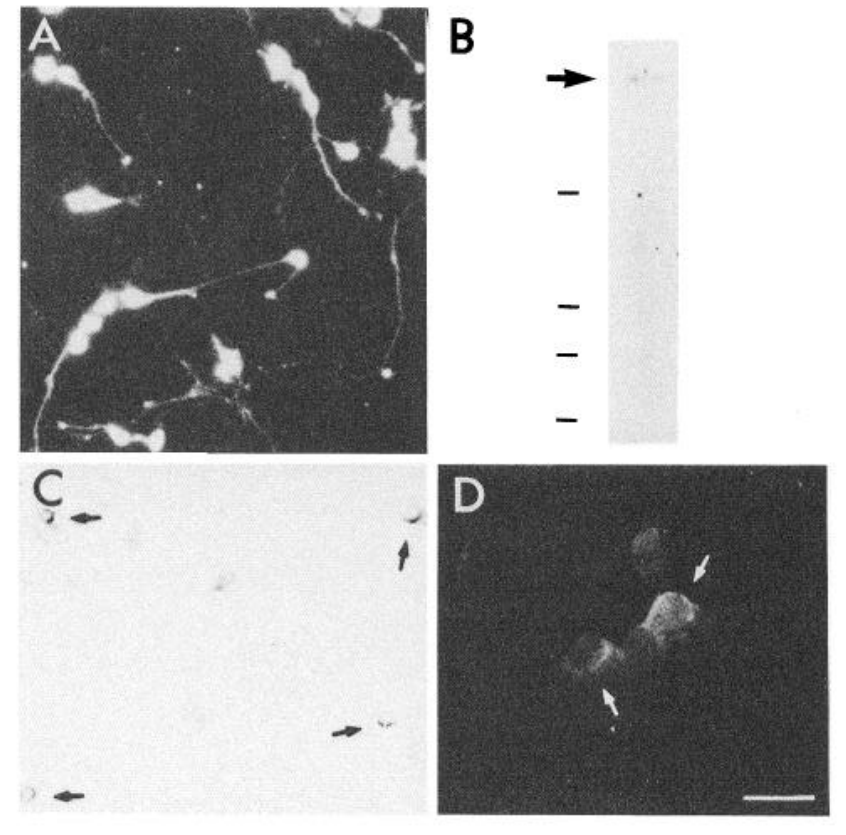

Figure 10. Expression of laminin $\alpha 2$ chain by embryonic chick retinal neurons in culture. Epithelia-free primary retinal cell cultures were prepared from $7 \mathrm{~d}$ chick embryos and processed for immunocytochemistry $(A, C, D)$ and immunoblotting $(B)$ as described in the Materials and Methods section. $A$ shows the neuronal composition of primary retinal cell cultures as revealed by labeling of cultured cells with a polyclonal antibody to $\beta$-tubulin. Laminin $\alpha 2$ chain expression was examined by immunoperoxidase $(C)$ or immunofluorescence $(D)$ staining using ascites fluid containing monoclonal anti- $\alpha 2$. Laminin $\alpha 2$ chain was detected on the surface of a subpopulation of live $(C)$ and fixed but unpermeabilized $(D)$ cultured chick retinal neurons. In addition, monoclonal anti- $\alpha 2$ recognizes $\mathrm{a} \approx 380 \mathrm{kDa}$ polypeptide in nonreduced extract of cultured retinal neurons $(B$, arrow). Molecular weight markers in $B$ correspond to $200 \mathrm{kDa}, 116 \mathrm{kDa}, 97 \mathrm{kDa}$, and $65 \mathrm{kDa}$. Scale bar represents $\approx 50 \mu \mathrm{m}$ in $A$ and $C, \approx 25 \mu \mathrm{m}$ in $D$.

inin $\alpha 2$ chain by type- 2 astrocytes in glial cultures derived from $12 \mathrm{~d}$ embryonic chick optic nerves. It remains to be investigated whether type- 2 astrocytes in mature optic nerves express laminin $\alpha 2$ chain on their surface. Finally, immunohistochemical and cell culture data presented in this study indicate that RGCs constitute additional cellular sources of laminin $\alpha 2$ chain during development. Expression of laminin $\alpha 2$ chain was detected on the surface of chick and mouse RGCs in retinal tissues and on the surface of embryonic chick RGCs in culture. Laminin-1 expression was also detected on mouse RGCs in retinal tissues and such an expression is at least imputable to synthesis of laminin $\beta 1$ chain by these cells (Sarthy and Fu, 1990). Hence, mouse RGCs could synthesize a laminin complex comprising an $\alpha 2$ chain, a $\beta 1$ chain, and perhaps an unidentified $\gamma$ chain. The situation is less clear for chick RGCs as no laminin-1 expression was detected on or surrounding RGCs in avian retina. Chick RGCs could synthesize the novel chicken laminin $\beta 3$ chain (O'Rear, 1992) instead of the laminin $\beta 1$ chain, but this remains to be demonstrated. Other groups have similarly reported laminin-like immunoreactivity in neurons (Liesi, 1983; Yamamoto et al., 1988; Hagg et al., 1989; Zhou, 1990; Suzuki et al., 1990; Jucker et al., 1993b). The role of neuronal laminin in the function of the nervous system however remains to be elucidated. As suggested by Hagg et al. (1989), neurons could produce in vivo their own laminin to use it among themselves for neuronal cell attachment and neurite outgrowth.
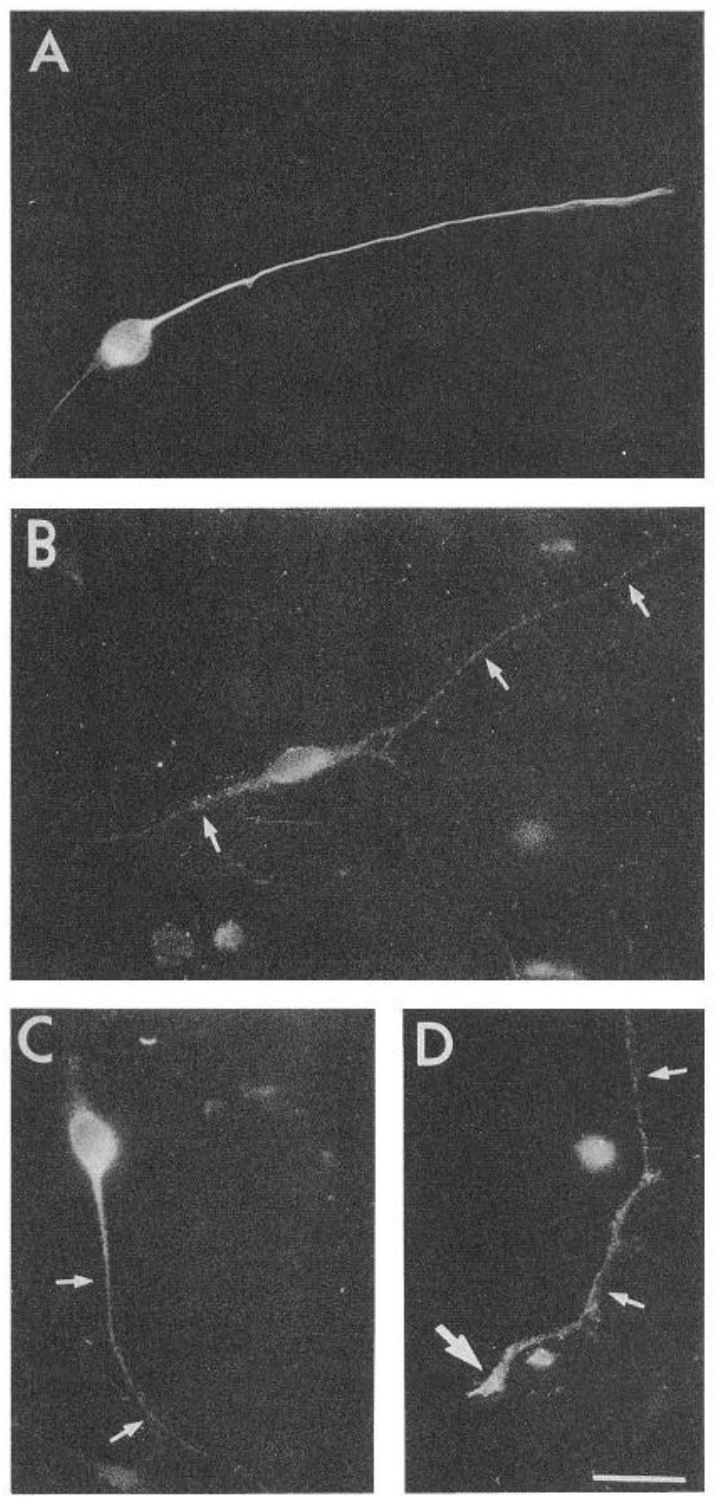

Figure 11. Expression of laminin $\alpha 2$ chain by embryonic chick RGCs in culture. Enriched cultures of RGCs were prepared from $7 \mathrm{~d}$ chick retinae by antibody-mediated adhesion of dissociated retinal cells (see the Materials and Methods section for details). Labeling of a cultured RGC with monoclonal antibody TUJ1 against $\beta$ III-tubulin, a chick RGC marker, is shown in $A$. Expression of laminin $\alpha 2$ chain by embryonic chick RGCs in culture was examined by immunofluorescence $(B-D)$ staining using ascites fluid containing monoclonal anti- $\alpha 2$. Laminin $\alpha 2$ chain was detected on the cell body $(B, C)$, neuritic processes $(B-D$; small arrows) and growth cone $(D$, large arrow) of live $(B)$ and fixed but unpermeabilized $(C, D)$ cultured chick RGCs. Scale bar represents $\approx 21 \mu \mathrm{m}$.

In conclusion, the spatiotemporal distribution of laminin $\alpha 2$ chain along avian and murine developing optic pathways is consistent with the hypothesis that laminin $\alpha 2$ chain-in a complex with non- $\beta 1$ and non- $\gamma 1$ laminin chains or as a monomer-may serve as an adhesive substrate for elongating RGC growth cones in vivo. Evidence that laminin-like molecules play a role in pioneering axonal migration in vivo was recently provided by Ishii et al., (1992). Their study indicates that mutation of the lamininrelated protein UNC-6 disrupts the dorsoventral migrations of cells and axons on the epidermis of $C$. elegans. In view of the reported expression of laminin $\alpha 2$ chain in three developing 
chick fiber bundles-optic nerve, anterior commissure, and tcctobulbar tract-it is reasonable to speculate that laminin $\alpha 2$ chain plays a role in fiber tract formation.

\section{References}

Blanks JC (1981) Cellular differentiation in the mammalian retina. In: The structure of the eye (Hollyfield JG, ed), pp 237-246. New York: Elsevier.

Bossy B, Bossy-Wetzel E, Reichardt LF (1991) Characterization of the integrin $\alpha 8$ subunit: a new integrin $\beta 1$-associated subunit, which is prominently expressed on axons and on cells in contact with basal laminae in chick embryos. EMBO J 10:2375-2385.

Bottstein JE, Skaper D, Varon S, Sato J (1980) Selective survival of neurons from chick embryo sensory ganglionic dissociates by use of a defined, serum-free medium. Exp Cell Res 125:183-190.

Burgeson RE, Chiquet M, Deutzmann R, Ekblom P, Engel J, Kleinman H, Martin GR, Meneguzzi G, Paulsson M, Sanes J, Timpl R, Tryggvason K, Yamada Y, Yurchenco PD (1994) A new nomenclature for the laminins. Matrix 14:209-211.

Chiu A, Espinosa de los Monteros A, Cole R, Loera S, De Vellis $J$ (1991) Laminin and s-laminin are produced and released by astrocytes, schwann cells and schwannomas in culture. Glia 4:11-24.

Cohen J, Johnson AR (1991) Differential effects of laminin and merosin on neurite outgrowth by developing retinal ganglion cells. I Cell Sci Suppl 15:1-17.

Cohen J, Burne JF, Winter J, Bartlett P (1986) Retinal ganglion cells lose response to laminin with maturation. Nature 322:465-467.

Cohen J, Burne JF, McKinlay C, Winter J (1987) The role of laminin and the laminin/fibronectin receptor complex in the outgrowth of retinal ganglion cell axons. Dev Biol 122:407-418.

de Curtis I, Quaranta V, Tamura RN, Reichardt LF (1991) Laminin receptors in the retina: sequence analysis of the chick integrin $\alpha 6$ subunit. J Cell Biol 113:405-416.

Douville PJ, Harvey WJ, Carbonetto S (1988) Isolation and partial characterization of high affinity laminin receptors in neural cells. $\mathbf{J}$ Biol Chem 263:14964-14969.

Ehrig K, Leivo I, Argraves WS, Ruoslahti E, Engvall E (1990) Merosin, a tissue-specific basement membrane protein, is a laminin-like protein. Proc Natl Acad Sci USA 87:3264-3268.

Eisenbarth GS, Walsh FS, Nirenberg M (1979) Monoclonal antibody to a plasma menbrane antigen of neurons. Proc Natl Acad Sci USA 76:4913-4917

Engvall E, Earwicker D, Day A, Muir D, Manthorpe M, Paulsson M (1992) Merosin promotes cell attachment and neurite outgrowth and is a component of the neurite-promoting factor of RN22 Schwannoma cells. Exp Cell Res 198:115-123.

Eriksdotter-Nilsson M, Björklund H, Olson L (1986) Laminin immunohistochemistry: a simple method to visualize and quantitate vascular structures in the mammalian brain. J Neurosci Methods 17:275286.

Fraser SE, Carhart MS, Murray BA, Chuong C-M, Edelmam GM (1988) Alterations in the Xenopus retinotectal projection by antibodies to Xenopus N-CAM. Dev Biol 129:217-230.

Goldberg S (1974) Studies on the mechanics of development of the visual pathways in the chick embryo. Dev Biol 36:24-43.

Green TL, Hunter DD, Chan W, Merlie JP, Sanes JR (1992) Synthesis and assembly of the synaptic cleft protein s-laminin by cultured cells. J Biol Chem 267:2014-2022.

Hagg T, Muir D, Engvall E, Varon S, Manthorpe M (1989) Lamininlike antigen in rat CNS neurons: distribution and changes upon brain injury and nerve growth factor treatment. Neuron 3:721-732.

Harris WA (1989) Local positional cues in the neuroepithelium guide retinal axons in embryonic Xenopus brain. Nature 339:218 220 .

Hinds JW, Hinds PL (1974) Early ganglion cell differentiation in the mouse retina: an electron microscopic analysis utilizing serial sections. Dev Biol 37:381-416.

Hunter DD, Porter BE, Bulock JW, Adams SP, Merlie JP, Sanes JR (1989) Primary sequnce of a motor neuron-selective adhesive site in the synaptic basal lamina protein s-laminin. Cell 59:905-913.

Hunter DD, Cashman N, Morris-Valero R, Bulock JW, Adams SP, Sanes JR (1991) An LRE (leucine-arginine-glutamate)-dependent mechanism for adhesion of neurons to s-laminin. J Neurosci 11:3960-3971.

Hunter DD, Llinas R, Ard M, Merlie JP, Sanes JR (1992a) Expression of s-laminin and laminin in the developing rat central nervous system. J Comp Neurol 323:238-251.

Hunter DD, Murphy MD, Olsson CV, Brunken WJ (1992b) S-Laminin cxpression in adult and devcloping retinae: a potential cue for photoreceptor morphogenesis. Neuron 8:399-413.

Hynes RO (1992) Integrins: versatility, modulation, and signalling in cell adhesion. Cell 69:11-25.

Ishii N, Wadsworth WG, Stern BD, Culotti JG, Hedgecock EM (1992) UNC-6, a laminin-related protein, guides cell and pioneer axon migrations in C. elegans. Neuron 9:873-881.

Jucker M, Bialobok P, Kleinman HK, Walker LC, Hagg T, Ingram DK (1993a) Laminin-like and laminin-binding protein-like immunoreactive astrocytes in rat hippocampus after transient ischemia. Ann NY Acad Sci 679:245-252.

Jucker M, Walker LC, Kibbey MC, Kleinman HK, Ingram DK (1993b) Localization of a laminin-binding protein in brain. Neuroscience 56: $1009-1022$

Keynes R, Cook G (1990) Cell-cell repulsion: clues from the growth cone? Cell 62:609-610.

LaVail JH, Cowan WM (1971) The development of the chick optic tectum. I. Normal morphology and cyto-architectonic development. Brain Res 28:391-419.

Lehwalder D, Jeffrey PL, Unsicker K (1989) Survival of purified embryonic chick retinal ganglion cells in the presence of neurotrophic factors. J Neurosci Res 24:329-337.

Leifer D, Lipton SA, Barnstable CJ, Masland RH (1984) Monoclonal antibody to Thy-1 enhances regeneration of processes by rat retinal ganglion cells in culture. Science 232:303-306.

Leivo I, Engvall E (1988) Mcrosin, a protein spccific for basement membranes of Schwann cells, striatedmuscle, and trophoblast, is expressed late in nerve and muscle development. Proc Natl Acad Sci USA 85:1544-1548.

Letourneau PC, Shattuck TA, Ressler AH (1986) Branching of sensory and sympathetic neurites in vitro is inhibited by treatment with taxol. J Neurosci 6:1912-1917.

Letourneau PC, Madsen AM, Palm SL, Furcht LT (1988) Immunoreactivity for laminin in the developing ventral longitudinal pathway of the brain. Dev Biol 125:135-144.

Liesi P (1983) Laminin in cultured mouse C1300 neuroblastoma cells: immunocytochemical localization by pre and postembedding electron microscope procedures. J Histochem Cytochem 31:755-764.

Liesi P (1985) Do neurons in the vertebrate CNS migrate on laminin. EMBO J 4:1163-1170.

Liesi P, Silver J (1988) Is astrocyte laminin involved in axon guidance in the mammalian CNS? Dev Biol 130:774-785.

Liesi P, Dahl D, Vaheri A (1983) Laminin is produced by early rat astrocytes in primary cultures. J Cell Biol 96:920-924.

Liesi P, Kaakkola S, Dahl D, Vaheri A (1984) Laminin is induced in astrocytes of adult brain by injury. EMBO J 4:683-686.

Mann K, Deutzmann R, Aumailley M, Timpl R, Raimondi L, Yamada Y, Pan T, Conway D, Chu M-L (1989)Amino acid sequence of mouse nidogen, a multidomain basement membrane protein with binding activity for laminin, collagen IV and cells. EMBO J 8:65-72.

McLean IW, Nakane PK (1974) Periodate-lysine-paraformaldehyde: a new fixative for immunoelectron microscopy. J Histochem Cytochem 22:1077-1083.

McLoon SC, McLoon LK. Palm SL, Furcht L'I (1988) Transient expression of laminin in the optic nerve of the developing rat. J Neurosci 8:1981-1990.

Morissette N, Carbonetto S (1993) Soc Neurosci Abstr 19:1086.

O'Rear JJ (1992) A novel laminin B1 chain variant in avian eye. J Biol Chem 267:20555-20557

Paulsson M, Saladin K (1989) Mouse heart laminin: purification of the native protein and structural comparison with Engelbreth-HolmSwarm tumor laminin. J Biol Chem 264:18726-18732.

Paulsson M, Saladin K, Engvall E (1991) Structure of laminin variants: the $300-\mathrm{kDa}$ chains of murine and bovine heart laminin are related to the human placenta merosin heavy chain and replace the A chain in some laminin variants. J Biol Chem 266:17545-17551.

Pei YF, Rhodin JAG (1970) The prenatal development of the mouse eye. Anat Rec 168:105-126.

Raff MC, Miller RH (1984) Glial cell development in the rat optic nerve. Trends Neurosci 7:469-472.

Raff MC, Fields KL, Hakomori S-I, Mirsky R, Pruss RM, Winter J (1979) Cell-type-specific markers for distinguishing and studying 
neurons and the major classes of glial cells in culture. Brain Res 174: 283-308.

Raff MC, Abney ER, Cohen J, Lindsay R, Noble M (1983) Two types of astrocytes in cultures of developing rat white matter: differences in morphology, surface gangliosides and growth characteristics. J Neurosci 3:1289-1300.

Rager GH (1980) Development of the retino-tectal projection in the chicken. Adv Anat Embryol Cell Biol 63:1-92.

Reh TA, Pitts E, Constantine-Paton M (1983) The organization of the fibers in the optic nerve of normal and tectum-less Rana pipiens. $J$ Comp Neurol 218:282-296.

Reichardt I.F, Tomaselli KI (1991) Extracellular matrix molecules and their receptors: functions in neural development. Annu Rev Neurosci $14: 531-570$

Reichardt LF, Bossy B, Carbonetto S, de Curtis I, Emmett C, Hall DE, Ignatius MJ, Lefcort F, Napolitano E, Large T, Neugebauer KM, Tomaselli KJ (1990) Neuronal receptors that regulate axon growth. Cold Sping Harbor Symp Quant Biol 55:341-350.

Reichardt LF, Bossy B, de Curtis I, Neugebauer KM, Venstrom K, Sretavan D (1992) Adhesive interactions that regulate development of the retina and primary visual projection. Cold Spring Harbor Symp Quant Biol 57:419-429.

Sanes JR (1989) Extracellular matrix molecules that influence neural development. Annu Rev Neurosci 12:491-516.

Sarthy PV, Fu M (1990) Localization of laminin B1 mRNA in retinal ganglion cells by in situ hybridization. J Cell Biol 110:2099-2108.

Serafini T, Kennedy TE, Galko MJ, Mirzayan C, Jessell TM, TessierLavigne M (1994) The netrins define a family of axon outgrowthpromoting proteins homologous to C. elegans UNC-6. Cell 78:409424.

Snow DM, Watanabe M, Letourneau PC, Silver J (1991) A chondroitin sulfate proteoglycan may influence the direction of retinal ganglion cell outgrowth. Development 113:1473-1485.

Sretavan DW (1990) Specific routing of retinal ganglion cell axons at the mammalian optic chiasm during embryonic development. J Neurosci $10: 1995-2007$.

Sretavan DW (1993) Pathfinding at the mammalian optic chiasm. Curr Opinion Neurobiol 3:45-52.

Sretavan DW, Reichardt LF (1993) Time-lapse video analysis of retinal ganglion cell axon pathfinding at the mammalian optic chiasm: growth cone guidance using intrinsic chiasm cues. Neuron 10:761777.

Suzuki H, Yamamoto T, Yamamoto H, Konno H, Iwasaki Y, Ohara Y, Terunuma H (1990) Intraneuron allaminin-like immunoreactivity in the human central nervous system. Brain Res 520:324-329.

Tawil NJ, Houde M, Blacher R, Esch F, Reichardt LF, Turner DC, Carbonetto $\mathrm{S}$ (1990) The $\alpha 1 \beta 1$ integrin heterodimer functions as a dual laminin/collagen receptor in neural cells. Biochem 29:6540-6544.

Taylor JSH (1990) The directed growth of retinal axons towards surgically transposed tecta in Xenopus; an examination of homing behaviour by retinal ganglion cell axons. Development 108:147-158.

Tomaselli KJ, Doherty P, Emmett CJ, Damsky CH, Walsh FS, Reichardt LF (1993) Expression of $\beta 1$ integrins in sensory neurons of the dorsal root ganglion and their functions in neurite outgrowth on two laminin isoforms. J Neurosci 13:4880-4888.

Towbin H, Staehelin T, Gordon J (1979) Electrophoresis transfer of proteins from polyacrilamide gels to nitrocellulose sheets: procedure and some applications. Proc Natl Acad Sci IJSA 76:4350-4354.

Tryggvason K (1993) The laminin family. Curr Opinion Cell Biol 5:877-882.

Varnum Finney B, Venstrom K, Muller U, Kypta R, Backus C, Chiquet M, Reichardt LF (1995) The integrin receptor $\alpha 8 \beta 1$ mediates interactions of embryonic chick motor and sensory neurons with tenascinC. Neuron 14:1213-1222.

Vuolteenaho R, Nissinen M, Sainio K, Byers M, Eddy R, Hirvonen H, Shows TB, Sariola H, Engvall E, Tryggvason K (1994) Human Iaminin $\mathbf{M}$ chain (merosin): complete primary structure, chromosomal assignment, and expression of the $\mathrm{M}$ and $\mathrm{A}$ chain in human fetal tissues. J Cell Biol 124:381-394.

Watanabe M, Rutishauser U, Silver J (1991) Formation of the retina ganglion cell and optic fibre layers. J Neurobiol 22:85-96.

Wujek JR, Haleem-Smith H, Yamada Y, Lipsky R, Tze Lan Y, Freese $\mathrm{E}$ (1990) Evidence that the B2 chain of laminin is responsible for the neurite outgrowth-promoting activity of astrocyte extracellular matrix. Dev Brain Res 55:237-247.

Yamamoto T, Iwasaki Y, Yamamoto H, Konno H, Isemura M (1988) Intraneuronal laminin-like molecule in the central nervous system demonstration of its unique differential distribution. J Neurol Sci 84: $1-13$.

Zhou FC (1990) Four patterns of laminin-immunoreactive structure in developing rat brain. Dev Brain Res 55:19-1-201. 